\title{
Propostas de melhorias no desenvolvimento de empreendimentos habitacionais a partir da aplicação do conceito de arquitetura do produto
}

\author{
Proposals for improvement in the development of housing \\ projects based on the application of the product \\ architecture concept
}

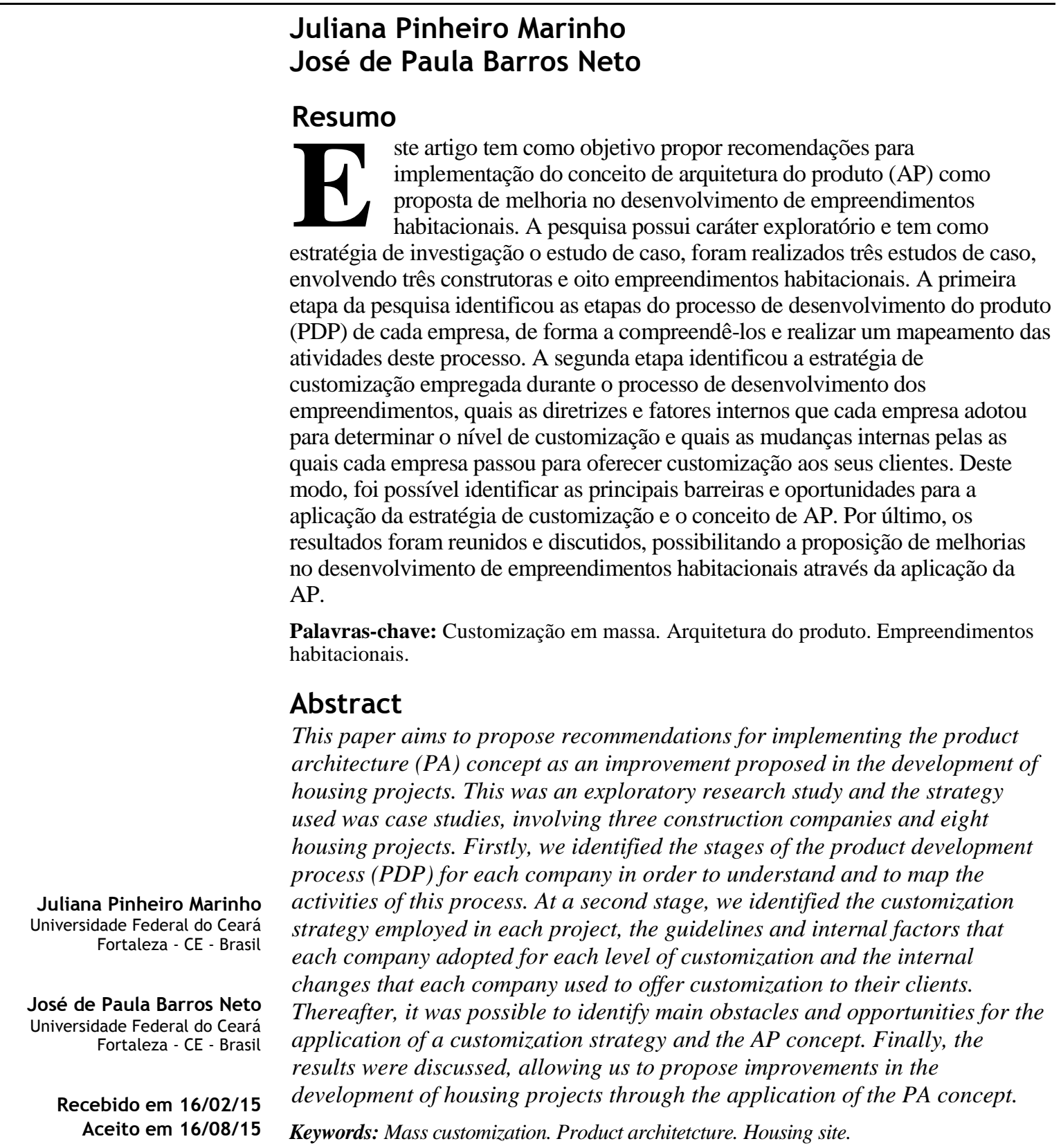




\section{Introdução}

As transformações dos comportamentos sociais, a diversidade de perfis de moradores e mudanças no modo de vida são fatores que apontam a atual heterogeneidade de realidades e são as principais causas da necessidade de mudança no desenho das unidades de habitação (BRANDÃO, 2002; TRAMONTANO; BENEVENTE, 2004). Como assinala Galfetti ${ }^{1}$ (1997 apud BRANDÃO, 2002), a habitação estereotipada destina-se a uma família padrão, um usuário médio que nunca existiu.

Estudos recentes sobre satisfação dos clientes e pós-ocupação apontam uma ampla gama de agrupamentos domiciliares em que grande parte das famílias não forma o agrupamento familiar básico (casal com dois filhos) (CHAVES; LEITE; FORMOSO, 2006; LACERDA; MARROQUIM; ANDRADE, 2011; MUSSI, 2011; XAVIER; BARBIRATO, 2011, CAIXA..., 2011). Essas pesquisas mostram a necessidade de melhorias na funcionalidade, possibilidade de expansão e customização da unidade habitacional, de forma a gerar maior satisfação nos moradores. Nessa tentativa de entregar produtos personalizados, destaca-se a customização em massa (CM), que se refere a uma estratégia de personalização de bens e serviços com custo e prazo de entrega semelhante a produtos padronizados (JIAO; MA; TSENG, 2001; ROCHA; FORMOSO; SANTOS, 2012).

No Brasil estão surgindo pesquisas sobre aplicação da estratégia de $\mathrm{CM}$ relacionada à produção habitacional, como no caso de estudos sobre a implementação (MACHADO; MORAES, 2008), elaboração de táticas (TILLMAN, 2008; TILLMANN; FORMOSO, 2008) e modelo para definição de estratégias de customização (ROCHA, 2011). Diversos autores reconhecem a necessidade de se produzirem habitações que atendam de forma adequada à necessidade dos moradores (BRANDÃO, 1997, 2002, TRAMONTANO; BENVENTE, 2004; TILLMANN; FORMOSO, 2008; XAVIER; BARBIRATO, 2011).

Em alguns desses estudos encontra-se o conceito de arquitetura do produto (AP) como forma de facilitar a aplicação da estratégia de CM (DU; JIAO; TSENG, 2001; HALMAN; HALMAN; ION, 2006; TILLMANN, 2008; ROCHA, 2011). AP é conceito fundamental para a aplicação da estratégia de customização e uma das atividadeschave para qualquer ação de desenvolvimento industrial de produtos (TILLMANN, 2008; ROCHA, 2011; DAHMUS; GONZALEZ-

\footnotetext{
${ }^{1}$ GALFETTI, G. G. Model apartments: experimental domestic
} cells. Barcelona: Gustavo Gili, 1997.
ZUGASTI; OTTO, 2001). A utilização desse conceito é um importante aspecto na concepção do produto, permitindo a intercambialidade entre as peças, facilitando a oferta de produtos customizados e garantindo a produtividade ao mesmo tempo em que cumpre as expectativas dos clientes (ROZENFELD et al., 2006; MUFFATTO; ROVEDA, 2002).

Portanto, se o objetivo da empresa construtora é adotar a estratégia da CM para obter melhores resultados em relação à satisfação do cliente, redução de custos e aumento da produtividade, a AP deve ser contemplada para que esse objetivo seja alcançado de forma eficiente. A AP irá auxiliar a aplicação da estratégia de $\mathrm{CM}$ porque envolve determinadas questões como facilidade de mudança do produto, capacidade de atingir certos tipos de desempenho técnico, divisão de recurso interno e externo, e o modo como o desenvolvimento é gerenciado e organizado (ULRICH, 1995). Para o referido autor, a AP é particularmente relevante para a pesquisa e desenvolvimento do produto que a empresa irá oferecer, uma vez que as decisões desse conceito são tomadas na fase inicial do processo.

Porém, o conceito de AP ainda não é bem compreendido por algumas empresas (DAHMUS; GONZALEZ-ZUGASTI; OTTO, 2001), principalmente quando aplicado na indústria da construção civil. Para atingir esses objetivos, a empresa deve tomar decisões sobre a variedade do produto, a padronização e a personalização que serão oferecidas aos clientes (MUFFATTO; ROVEDA, 2002). Por essas razões, a empresa precisa avaliar sua estratégia de produto e a importância da AP (MUFFATTO; ROVEDA, 2002).

Esta pesquisa investiga a implementação da AP voltada para habitações, além de saber quais os entraves e oportunidades na utilização de AP no processo de desenvolvimento do empreendimento aplicando a estratégia da CM. Esta pesquisa busca ainda saber quais são as melhorias proporcionadas pela aplicação desse conceito.

A formulação do problema da pesquisa foi baseada na identificação da necessidade de oferecer opções mais customizáveis nas unidades habitacionais (UH) oferecidas aos usuários pelas construtoras de empreendimentos habitacionais. $\mathrm{O}$ setor da construção de edifícios residenciais necessita da compatibilidade entre a possibilidade de oferecer opções ao usuário e atendê-lo por meio de plantas flexíveis e personalizadas, ao mesmo tempo em

106 Marinho, J. P.; Barros Neto, J. de P. 
que visa garantir os aspectos de construção racionalizada (BRANDÃO, 2002).

Este trabalho aponta ações que aprofundam o conceito de AP como proposta de melhoria no desenvolvimento de empreendimentos habitacionais.

A quantidade de empreendimentos analisados na pesquisa limitou-se às empresas construtoras que aceitaram participar do estudo e que utilizavam a estratégia de $\mathrm{CM}$ em seus empreendimentos, situadas em Fortaleza, CE. Outro limitante desta pesquisa foi o impedimento, por parte da empresa, para o acesso dos processos internos e aos documentos relevantes ao estudo. As bases de dados devem ser compatíveis para possibilitar as análises comparativas.

O foco desta pesquisa foi o espaço privado das habitações, ou seja, a unidade habitacional. Essa delimitação ocorre pelo fato de que o conceito de customização se relaciona com as necessidades específicas de cada usuário, influenciando a produção de bens diferenciados para atender à diversidade de requisitos. Portanto, esta pesquisa limitou-se a investigar o espaço privado, pois esse representa o espaço do empreendimento no qual o cliente tem a possibilidade de intervir e adequar para atender a suas necessidades. Dessa forma, não integram o escopo desta pesquisa os aspectos do empreendimento que não podem ser alterados de acordo com a necessidade individual do morador, excluindo-se, dessa maneira, as áreas coletivas e públicas dos empreendimentos.

\section{Processo de Desenvolvimento do Produto}

O processo de desenvolvimento do produto (PDP) é um conjunto de atividades realizadas por diferentes setores funcionais de uma empresa necessárias para a concepção, o desenho e a construção de um produto. Essas atividades se iniciam com a percepção de uma oportunidade no mercado e têm seu fim na produção, venda e distribuição do produto (ULRICH; EPPINGER, 2000; AMARAL, 2002; TZORTZOPOULOS, 2004; ROZENFELD et al., 2006).

Para este trabalho, o PDP é parte integrante de um macroprocesso, considerando os diferentes processos contidos para a provisão habitacional. Dessa forma, o PDP se insere no processo de provisão habitacional através do planejamento, desenvolvimento e gerenciamento de atividades diretas e correlatas capazes de fornecer à população um produto que está de acordo com as necessidades do mercado.

\section{Customização em Massa}

Nas décadas de 1960 e 1970 o mercado tornou-se ainda mais complexo e a concorrência mais intensa, fazendo com que a rapidez de entrega da mercadoria ao cliente fosse algo necessário (SHIVANAND; BENAL; KOTI, 2006). Uma nova estratégia foi formulada, a customização, em que as empresas tiveram de se adaptar a um ambiente mais flexível e, através de suas operações, satisfazer diferentes segmentos do mercado. Foi Stan Davis quem primeiro cunhou o termo customização em massa, em seu livro Future Perfect, lançado em 1987 (DURAY et al., 2000; SILVEIRA; BORENSTEIN; FOGLIATTO, 2001; JIAO; MA; TSENG, 2001; TILLMANN, 2008). Essa inovação está relacionada ao esforço de ganhar vantagem competitiva (SHIVANAND; BENAL; KOTI, 2006).

É nesse contexto, a partir da década de 1980, que Pine (1994) aponta o surgimento do processo que combina simultaneamente a produção em massa com a produção sob encomenda, denominada customização em massa (CM). A adoção dessa estratégia pode ser vista como uma evolução natural das empresas, tornando os processos cada vez mais flexíveis e otimizados em relação à qualidade e custos (SILVEIRA; BORENSTEIN; FOGLIATTO, 2001)

A crescente demanda por variedade e a maior flexibilidade incentivam as empresas de construção de habitações a considerar novos tipos de projeto de produtos e processos (HALMAN; VOORDIJK; REYMEN, 2008, HOFMAN; HALMAN; ION, 2006), criando um estreitamento das relações entre cliente e construtora que passou a incluir solicitações para modificações do projeto, ou seja, fez-se emergir um novo condicionante no processo produtivo da indústria da construção civil: a personalização e a possibilidade de escolha (BRANDÃO, 2002).

Atualmente, os projetos da construção civil são organizados em cadeias de suprimento temporárias que têm implicação direta nas estratégias de customização que podem ser desenvolvidas (KOSKELA, 2000; ROCHA, 2011). Nessas condições Rocha (2011) afirma que é improvável que uma única estratégia de customização seja utilizada para um grande volume de produtos, como acontece no setor manufatureiro, pois essas estratégias variam de um projeto para outro, dependendo das metas específicas e das partes envolvidas.

No Brasil as construções necessitam de uma oferta de espaços mais flexíveis, por ser considerado um importante aspecto para a permanência da família 
no imóvel em caso de crescimento familiar (TILLMANN, 2008). Essa flexibilidade, ou postponement, permite que os sistemas de produção possam lidar com as variantes do produto criado sob a estratégia de customização (FEITZINGER; LEE, 1997; ROCHA, 2011).

\section{Arquitetura do Produto}

Para melhor apreensão do conceito de arquitetura do produto (AP) são descritas algumas definições encontradas na literatura:

(a) Wang e Kimble ${ }^{2}$ (2010 apud ROCHA, 2011) definem AP como uma representação conceitual dos componentes físicos utilizados para a fabricação de um produto, juntamente com as interações entre eles que afetam seu funcionamento;

(b) Rozenfeld et al. (2006) definem que AP é a maneira como os elementos funcionais, ou seja, sistemas, subsistemas e componentes estão arranjados e como eles se relacionam através de suas interfaces; e

(c) para Ulrich (1995), AP é o método pelo qual a função de um produto é atribuída aos componentes físicos, ou seja, como os elementos funcionais, através de um mapeamento dos componentes físicos e suas especificações, irão interagir através de suas interfaces.

Ulrich (1995) ainda afirma que a AP possui duas tipologias: a arquitetura modular e a arquitetura integral. $\mathrm{Na}$ arquitetura modular existe $\mathrm{o}$ mapeamento um para um a partir dos elementos funcionais para os componentes físicos (ULRICH, 1995; SALVADOR; $\quad$ FORZA; RUNGTUSANATHAM, 2002). Na arquitetura integral existe um complexo mapeamento (sem um para um) dos elementos funcionais para os componentes físicos e a ligação dos componentes através das interfaces. Para Rocha (2011), esse tipo de arquitetura não é adequado para as estratégias de customização, pois exigiria que um desenho de produto fosse desenvolvido a partir do zero para cada pedido, comprometendo os critérios de custo e entrega de forma semelhante à dos produtos produzidos em massa. Embora a maioria dos produtos não possa ser classificada estritamente como modular ou integral, o projeto pode assumir diferentes arquiteturas (ROCHA, 2011).

Uma implicação desse conceito é que, na medida em que os diferentes segmentos de mercado exigem produtos moderadamente diferentes, variantes de produtos voltados para cada um dos

${ }^{2}$ WANG, H.; KIMBLE, C. Low-cost strategy through product architecture: lessons from China. Journal of Business Strategy, v. 31, n. 3 , p. $12-20,2010$. segmentos podem diferir em um ou mais módulos, e o resto do produto se mantém inalterado (SALVADOR, 2007). Dessa forma, Salvador (2007) afirma que o objetivo da modularidade do produto é possuir produtos distintos, mas que as partes que criam essas diferenciações sejam minimizadas.

\section{Arquitetura modular}

A necessidade de oferecer vários elementos de customização exige que a AP permita a modularização do portfólio para viabilizar o projeto (DU; JIAO; TSENG, 2001; HOFMAN; HALMAN; ION, 2008; HALMAN; VOORDIJK; REYMEN, 2008; ROCHA, 2011). A arquitetura modular oportuniza as empresas a aumentar o nível da entrega de produtos que sejam diferenciados, satisfazendo os mais variados requisitos dos clientes, sem haver impactos substancialmente negativos, pois os custos de produção são minimizados pela reutilização dos módulos em múltiplos projetos (SALVADOR; FORZA; RUNGTUSANATHAM, 2002; HOFMAN; VOORDIJK; HALMAN, 2009).

$\mathrm{O}$ desenho do produto envolve o agrupamento de vários componentes de tal modo que os módulos resultantes sejam eficazes para a empresa. Uma arquitetura ideal é aquela em que as partes do produto sejam módulos práticos e úteis (DAHMUS; GONZALEZ-ZUGASTI; OTTO, 2001), classificados em:

(a) módulos de produtos: compõem os subsistemas agrupados como uma unidade que apresenta funções identificáveis; e

(b) portfólio de módulos: são módulos de produtos que são utilizados em múltiplos produtos.

Em se tratando de projetos habitacionais, a modularidade e a variedade podem ser alcançadas de duas maneiras: pela variação das partes que pertencem a uma plataforma modular que é aproveitada em vários projetos, ou variando as partes que estão incluídas no nível do projeto (HOFMAN; VOORDIJK; HALMAN, 2009). Para Hofman, Voordijk e Halman (2009), o desenvolvimento de uma plataforma modular deve ser considerado apenas quando há possibilidades claras para a empresa de construção e seus fornecedores de reutilizá-la em projetos.

\section{Plataforma}

A chave para a flexibilidade, eficiência e variedade é a identificação, aproveitamento e partilha de pontos comuns: plataforma, módulos, mercadoalvo e processos usados para entregar produtos e projetos (HALMAN; VOORDIJK; REYMEN, 
2008; HOFMAN; VOORDIJK; HALMAN, 2009). Para Halman, Halman e Ion (2006), a adoção de uma AP baseada na plataforma é uma opção promissora que leva as empresas de construção a considerar novos tipos de desenho de produtos e processos.

Uma definição geral de plataforma é um conjunto relativamente grande de componentes de produtos, fisicamente conectados como um subconjunto estável e comum aos diferentes modelos finais (MEYER; LEHNERD, $1997^{3}$ apud MUFATTO; ROVEDA, 2002). O termo "plataforma" se refere à configuração específica de um sistema de produção de modo a gerar facilmente, a partir dele, a variedade desejada de produtos (HALMAN; VOORDIJK; REYMEN, 2008).

No setor habitacional da construção civil a plataforma pode ser entendida como a estruturabase da unidade habitacional que irá receber os diferentes módulos predeterminados pelas opções de plantas customizáveis, ou seja, a plataforma pode ser considerada o sistema estrutural, as instalações elétricas e hidráulicas que se repetem em todas as unidades habitacionais de um empreendimento. Embora os estudos sobre plataforma de produtos tenham aumentado consideravelmente a partir do final da década de 90, sua aplicação no setor da habitação continua a ser uma subárea pouco pesquisada (VEENSTRA; HALMAN; VOORDIJK, 2006).

A criação de vários produtos que utilizam a aplicação da plataforma é denominada de arquitetura de família de produtos (PFA - Product Family Architcture), que se refere a um conjunto de produtos semelhantes que são derivados de uma plataforma comum, mas que possuem características específicas para atender às necessidades dos clientes (SILVEIRA; SANTOS, 2011; DU; JIAO; TSENG, 2001).

Sob a égide da PFA, o projeto das famílias de produtos de manifesta por meio da derivação das variantes desse produto. Isso permite que o cliente realize suas escolhas dentro de um conjunto de opções com características distintas e definidas previamente pelo construtor. No caso do projeto de habitações essas escolhas podem ser apresentadas para os clientes por meio de opções de plantas, opções de revestimentos, opções de louças sanitárias e outros.

\section{Método da pesquisa}

A pesquisa possui caráter exploratório, uma vez que a aplicação da AP no processo de $\mathrm{CM}$ na construção civil é pouco conhecida. Como estratégia de investigação foi realizado o estudo de caso, precedido de uma revisão bibliográfica, como forma de entender e propor melhorias no processo de desenvolvimento de empreendimentos habitacionais a partir da aplicação da AP.

O processo de desenvolvimento da pesquisa foi dividido em três etapas, conforme indica a Figura 1.

Para o desenvolvimento desta pesquisa foram desenvolvidos três estudos de caso, envolvendo três construtoras e oito empreendimentos habitacionais. É importante ressaltar que a quantidade de empreendimentos analisados na pesquisa limitou-se às empresas construtoras que aceitaram participar do estudo e que utilizavam a estratégia de $\mathrm{CM}$ em seus empreendimentos.

A etapa A teve como objetivo identificar as etapas do PDP de cada empresa, de forma a compreendêlo e realizar um mapeamento das atividades desse processo. Para a realização dessa etapa foram realizadas reuniões e entrevistas com funcionários do setor técnico das empresas, para coletar dados referentes ao PDP.

A etapa $\mathrm{B}$ foi desenvolvida concomitantemente à etapa A. Para a realização dessa etapa também foram feitas reuniões e entrevistas com funcionários do setor responsável e seus colaboradores. Essa etapa teve como objetivo identificar a estratégia de customização empregada durante o processo de desenvolvimento dos empreendimentos, identificar as diretrizes e fatores internos que cada empresa adota para determinar o nível de customização empregado e quais as mudanças internas pelas quais cada empresa passou para oferecer customização a seus clientes. Desse modo foi possível identificar as principais barreiras e oportunidades para a aplicação da estratégia de customização e de AP.

Por último os resultados foram reunidos e discutidos, possibilitando a proposição de melhorias no desenvolvimento de empreendimentos habitacionais através da aplicação da AP.

\section{Resultados e discussões PDP das empresas envolvidas}

A Figura 2 apresenta um mapeamento das principais etapas do PDP realizado pelas empresas analisadas. As etapas são descritas de forma linear,

${ }^{3}$ MEYER, M. H.; LEHNERD, A. P. The power of product platforms: building value and cost leadership. New York: The FPress, 1997. 
no entanto pode haver descontinuidade no processo, ou etapas que ocorram de forma concomitante, pois o processo não obedece a uma estrutura rígida. Dessa forma é possível analisar em quais etapas a arquitetura do produto pode ser mais bem aplicada.

\section{Estudo de caso 1: empreendimento VGL}

No empreendimento VGL da Empresa A foram identificados os módulos em cada opção de planta ofertada na customização (Figuras 3 a 5).

Figura 1 - Delineamento do processo da pesquisa

\begin{tabular}{|c|c|c|}
\hline $\begin{array}{l}\quad \text { ETAPA } \\
\quad \text { A } \\
\text { Descritiva } \\
\text { Exploratória } \\
\text { Compreensão do } \\
\text { PDP }\end{array}$ & \begin{tabular}{l}
$\quad$ ETAPA \\
\multicolumn{1}{c}{ B } \\
Descritiva \\
Exploratória \\
Compreensão e \\
análise das práticas \\
de Customização
\end{tabular} & $\begin{array}{l}\text { Discussão dos } \\
\text { resultados }\end{array}$ \\
\hline \multicolumn{2}{|c|}{ ESTUDOS DE CASO } & sobre AP \\
\hline \multicolumn{2}{|c|}{ REVISÃO } & \\
\hline
\end{tabular}

Figura 2 - Processo de Desenvolvimento do Produto

PROCESSO DE DESENVOLVIMENTO DE PRODUTOS

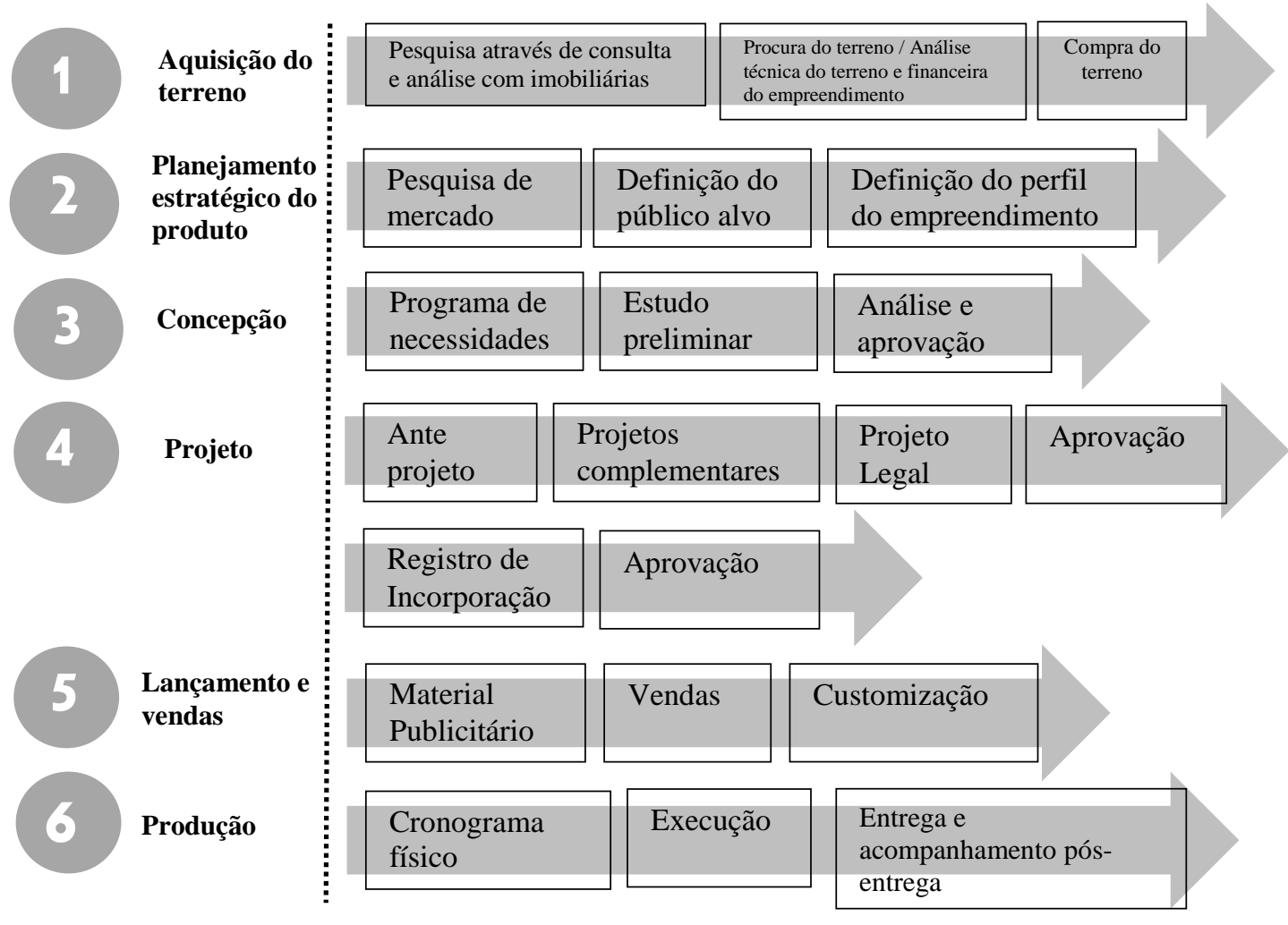


Figura 3 - Identificação dos módulos Opção 1 do empreendimento VLG - estudo de caso 1

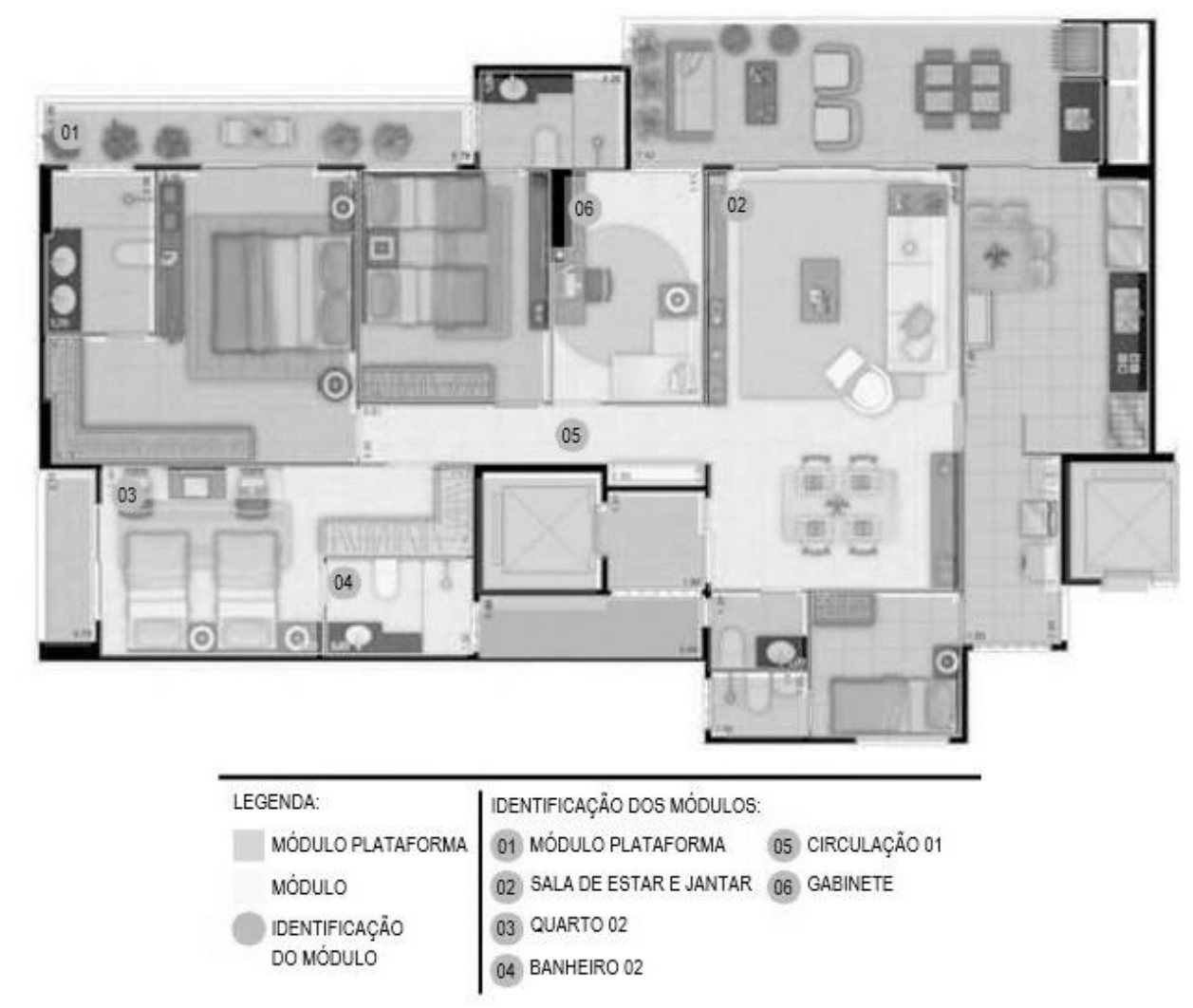

Figura 4 - Identificação dos módulos Opção 2 do empreendimento VLG - estudo de caso 1

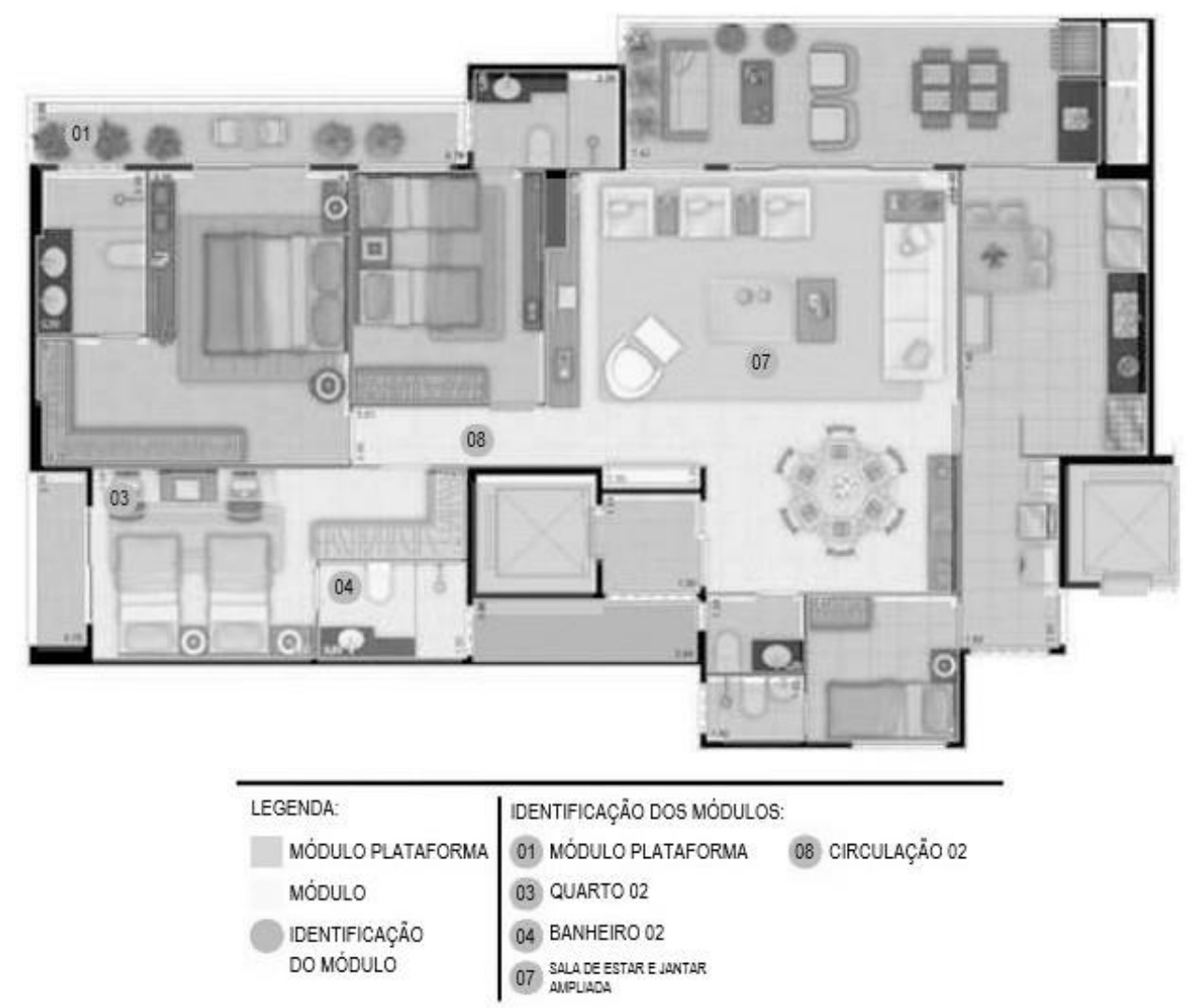


Figura 5 - Identificação dos módulos Opção 3 do empreendimento VLG - estudo de caso 1

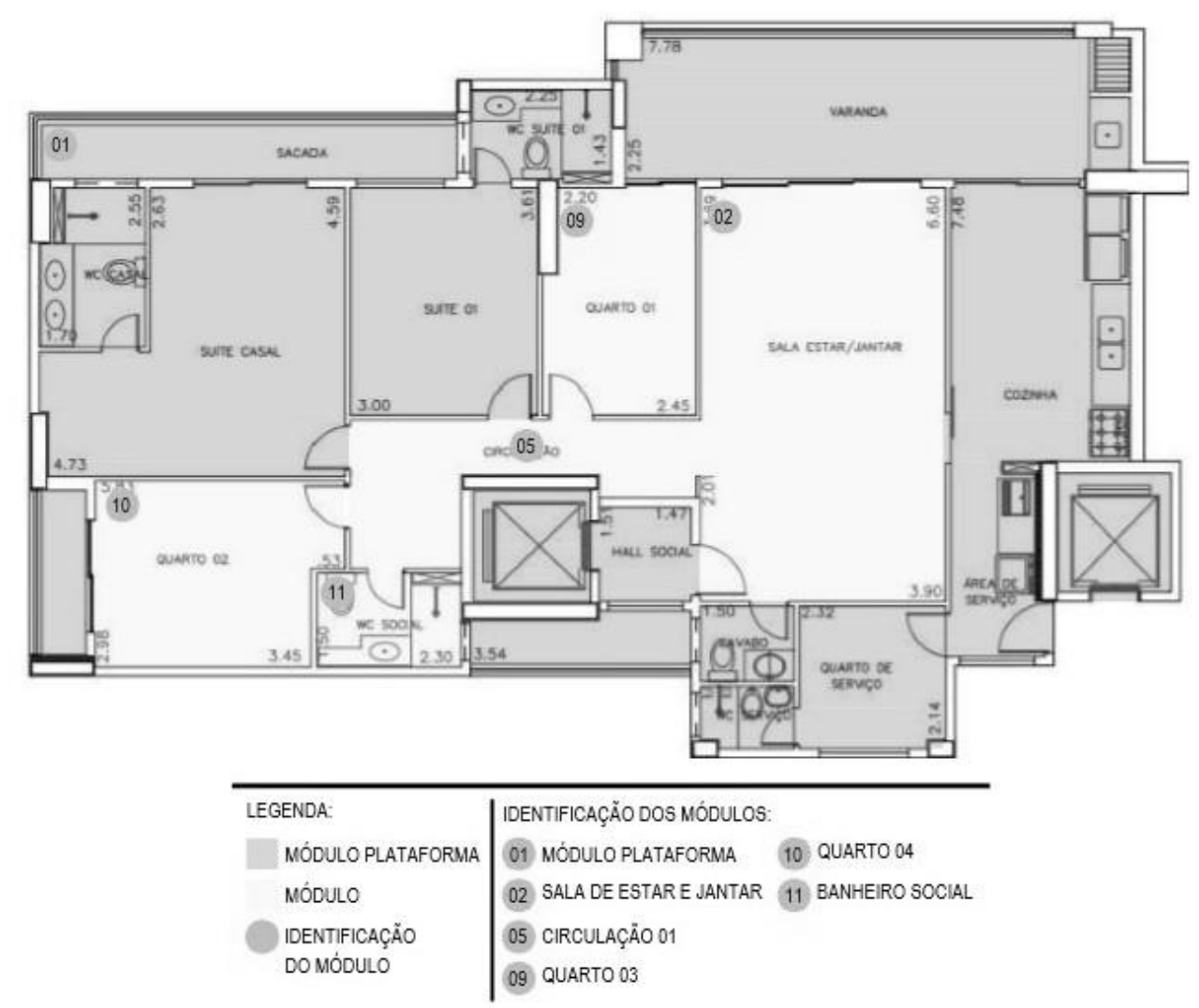

Na Tabela 1 é apresentada uma lista com todos os módulos identificados nas três opções.

Os módulos de um mesmo ambiente formam as famílias, identificadas na Tabela 2 .

Analisando a Família B, pode-se afirmar que a intercambialidade entre os módulos foi bemsucedida, porque, seguindo os princípios do conceito de AP, os módulos apresentaram interações geométricas que exigem a modificação de um pequeno conjunto de elementos. Uma melhoria que poderia ser sugerida nessa família é em relação às instalações elétricas desses módulos. Podemos observar que entre os módulos 6 e 9 , gabinete e quarto 3 há a possibilidade de desenvolver o mesmo projeto elétrico para as duas funções.

A Família C apresentou boa interface entre os módulos, porém a diminuição da área do quarto (no módulo 10) proporcionou aumento na área de circulação (módulo 5), que em termos de projeto não agrega valor porque não há aumento de área em um espaço de convivência do apartamento. Com base nessa análise, podemos observar que o apartamento perdeu uma suíte e ficou com um banheiro e lavabo que atender à área social. $\mathrm{O}$ banheiro 1, pertencente à plataforma, poderia ser projetado para atender tanto ao quarto 1 como aos módulos 6 e 9.

Na Família D, composta dos módulos 4 e 11, observa-se alteração nas instalações hidráulicas, considerada uma interação entre os componentes mais complexa. Essa alteração exige uma decisão do cliente antes mesmo da concretagem da laje. $\mathrm{O}$ indicado é trabalhar com um mesmo módulo que possa atender a todas as opções de planta, diminuindo assim a complexidade do módulo e o mapeamento dos componentes.

\section{Estudo de caso 1: empreendimento LLC}

A seguir é apresentada a identificação dos módulos em cada opção de planta desenvolvida para o empreendimento LLC da Empresa A (Figuras 6 a 8). 
Tabela 1 - Módulos do empreendimento VLG - estudo de caso 1

\begin{tabular}{c|l}
\hline MÓDULO & \multicolumn{1}{c}{ AMBIENTE } \\
\hline $\mathbf{0 1}$ & $\begin{array}{l}\text { Plataforma: varandas, sacadas, hall social, cozinha, área de serviço, quarto e banheiro de } \\
\text { serviço, lavabo, quarto e banheiro de casal, quarto 1, banheiro 1 }\end{array}$ \\
\hline $\mathbf{0 2}$ & Sala de estar e jantar \\
\hline $\mathbf{0 3}$ & Quarto 2 \\
\hline $\mathbf{0 4}$ & Banheiro 2 \\
\hline $\mathbf{0 5}$ & Circulação tipo 1 \\
\hline $\mathbf{0 6}$ & Gabinete \\
\hline $\mathbf{0 8}$ & Sala de estar e jantar ampliada \\
\hline $\mathbf{0 9}$ & Circulação tipo 2 \\
\hline $\mathbf{1 0}$ & Quarto 3 \\
\hline $\mathbf{1 1}$ & Quarto 4 \\
\hline
\end{tabular}

Tabela 2 - Famílias de módulos do empreendimento VLG - estudo de caso 1

\begin{tabular}{c|l}
\hline FAMÍLIA & \multicolumn{1}{c}{ MÓDULO } \\
\hline A & 01 (Plataforma) \\
B & 02, 05, 06, 07, 08 e 09 \\
C & 03 e 10 \\
D & 04 e 11 \\
\hline
\end{tabular}

Figura 6 - Identificação dos módulos Opção 1 do empreendimento LLC - estudo de caso 1

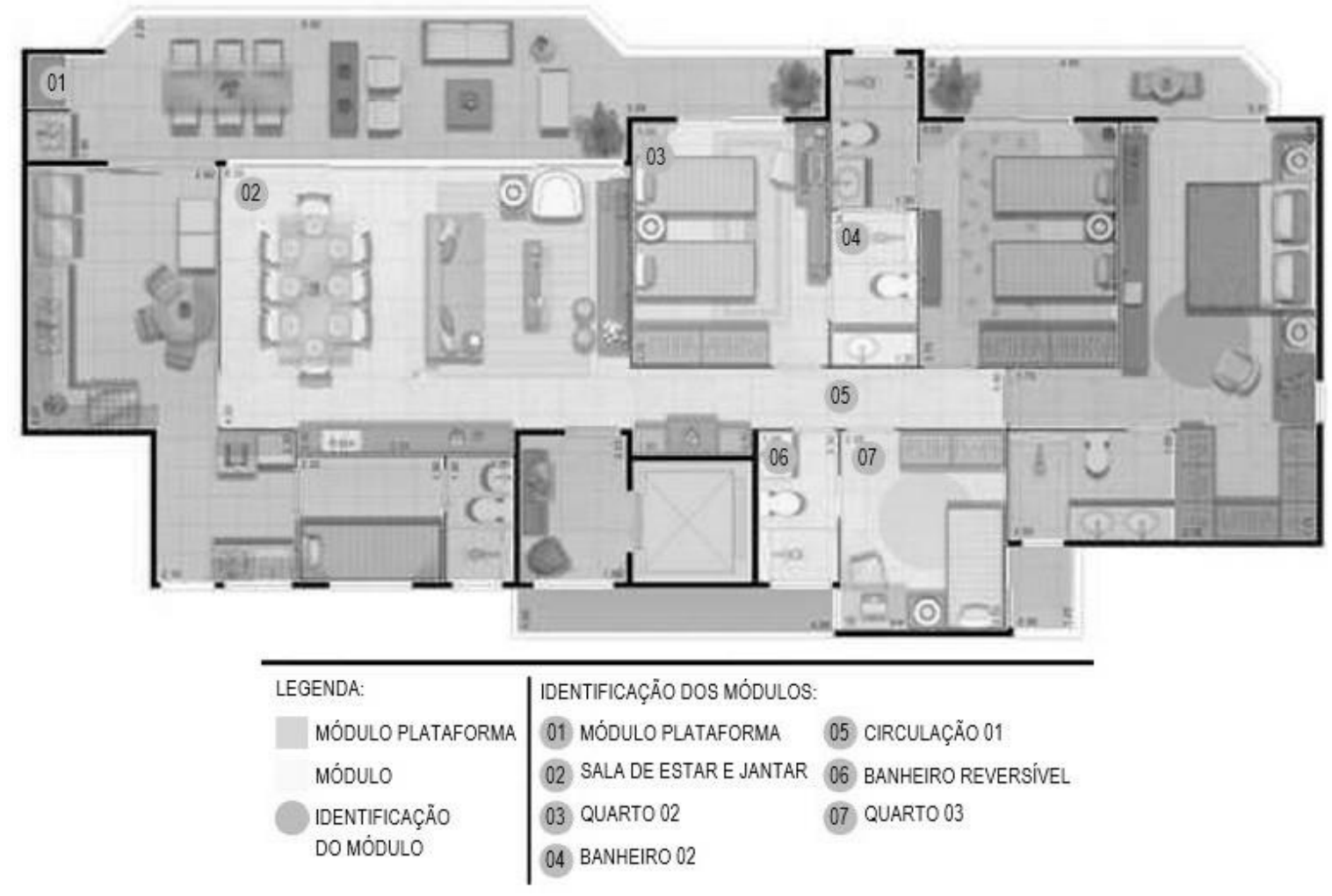


Figura 7 - Identificação dos módulos Opção 2 do empreendimento LLC - estudo de caso 1

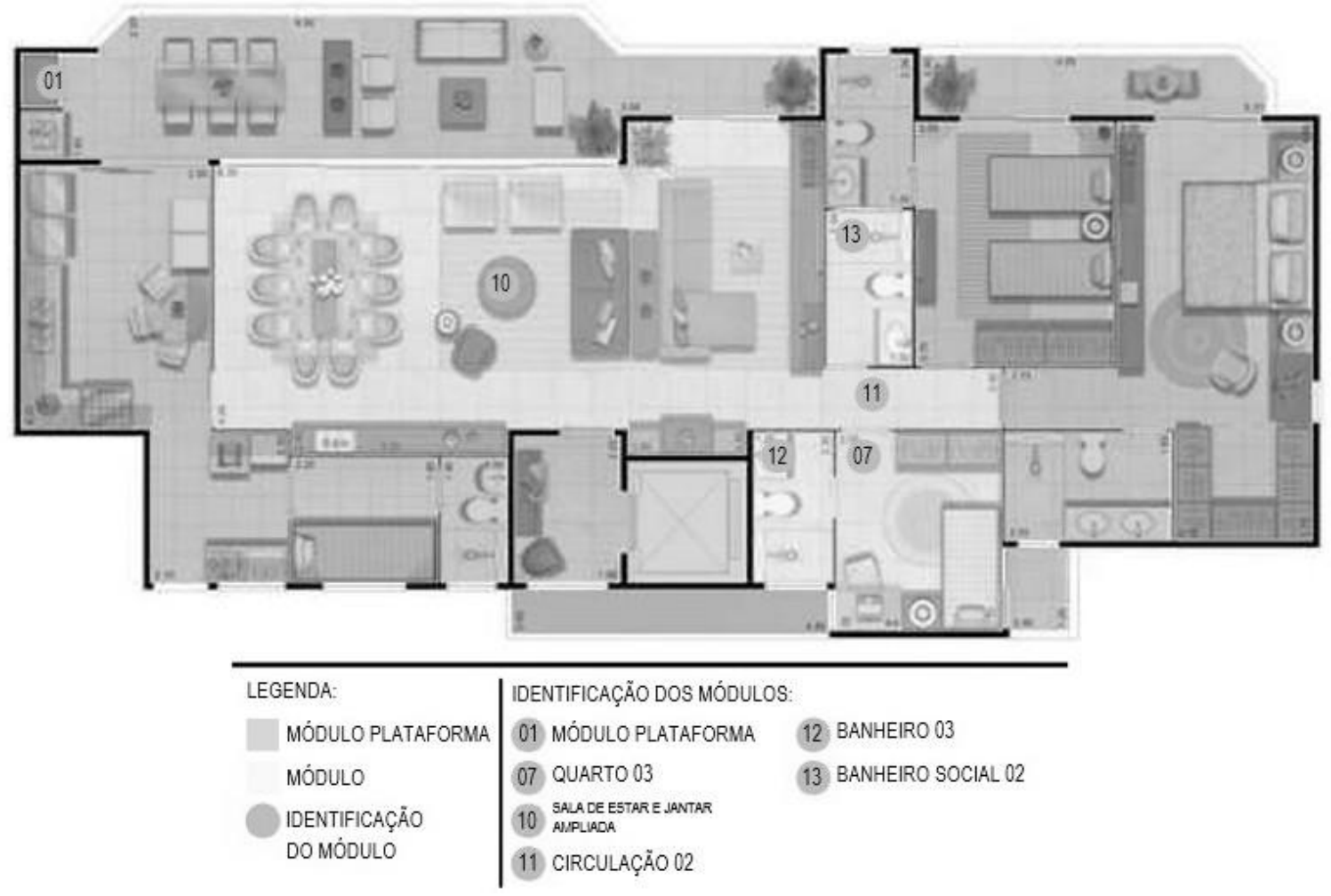

Figura 8 - Identificação dos módulos Opção 3 do empreendimento LLC - estudo de caso 1

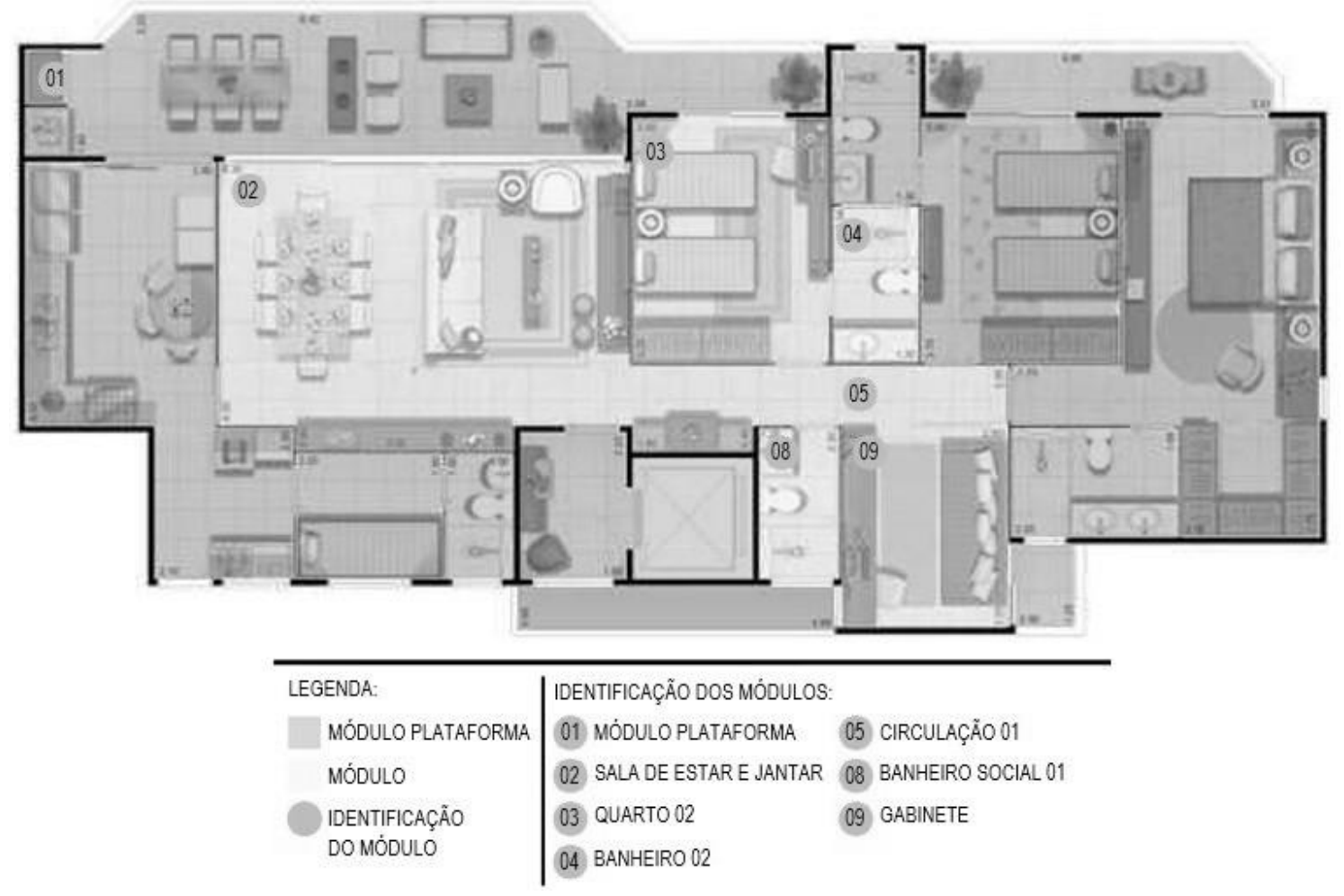


Na Tabela 3 é apresentada uma lista com todos os módulos identificados nas três opções.

As famílias de módulos estão identificadas na Tabela 4.

A Família B possui módulos com uma boa interação geométrica entre as interfaces, o mapeamento dos módulos apresenta modificações de um pequeno número de elementos, e os módulos são bem utilizados nas três opções de planta propostas. Os módulos da Família C possuem funções similares, ambos são banheiros, mas atendem a diferentes usuários. A solução geométrica entre os componentes se torna complexa no momento em que é necessária a mudança do ponto hidráulico da pia, necessitando uma decisão antecipada da opção de planta e uma possível interferência no setor de produção.

Nesse caso o projeto poderia prever para ambos os módulos a mesma solução de pontos hidráulicos, alterando somente a posição das portas de acesso.
Exatamente como acontece na Família D, nessa situação houve uma interação bem-sucedida entre os módulos, pois o mapeamento dos componentes facilitou a mudança de módulos com a menor interferência possível. Na Família E os módulos apresentam interações de baixa complexidade, porém o projeto requer alterações nos pontos elétricos, o que pode afetar o setor da produção. O indicado, então, é elaborar um leiaute que utilize um projeto elétrico capaz de atender aos dois módulos.

\section{Estudo de caso 2: empreendimento SBL}

Nas figuras a seguir são identificados os módulos desenvolvidos em cada opção de planta para o empreendimento SBL da Empresa B (Figuras 9 e 10).

Na Tabela 5 é apresentada uma lista com todos os módulos identificados nas duas opções.

Tabela 3 - Módulos do empreendimento LLC - estudo de caso 1

\begin{tabular}{c|l}
\hline MÓDULO & \multicolumn{1}{c}{ AMBIENTE } \\
\hline $\mathbf{0 1}$ & $\begin{array}{l}\text { Plataforma: varandas, sacadas, hall social, cozinha, área de serviço, quarto e } \\
\text { banheiro de serviço, quarto e banheiro de casal, quarto 1, banheiro 1 }\end{array}$ \\
\hline $\mathbf{0 2}$ & Sala de estar e jantar \\
\hline $\mathbf{0 3}$ & Quarto 2 \\
\hline $\mathbf{0 4}$ & Banheiro 2 \\
\hline $\mathbf{0 5}$ & Circulação tipo 1 \\
\hline $\mathbf{0 7}$ & Banheiro reversível \\
\hline $\mathbf{0 8}$ & Quarto 3 \\
\hline $\mathbf{0 9}$ & Banheiro social 1 \\
\hline $\mathbf{1 1}$ & Gabinete \\
\hline $\mathbf{1 2}$ & Sala de estar e jantar ampliada \\
\hline $\mathbf{1 3}$ & Circulação tipo 2 \\
\hline
\end{tabular}

Tabela 4 - Famílias de módulos do empreendimento LLC - estudo de caso 1

\begin{tabular}{c|l}
\hline FAMÍLIA & \multicolumn{1}{c}{ MÓDULO } \\
\hline $\mathbf{A}$ & 01 (Plataforma) \\
$\mathbf{B}$ & 02, 03, 05, 10 e 11 \\
$\mathbf{C}$ & $04 \mathrm{e} 13$ \\
$\mathbf{D}$ & 06, 08 e 12 \\
$\mathbf{E}$ & 07 e 09 \\
\hline
\end{tabular}


Figura 9 - Identificação dos módulos Opção 1 do empreendimento SBL - estudo de caso 2

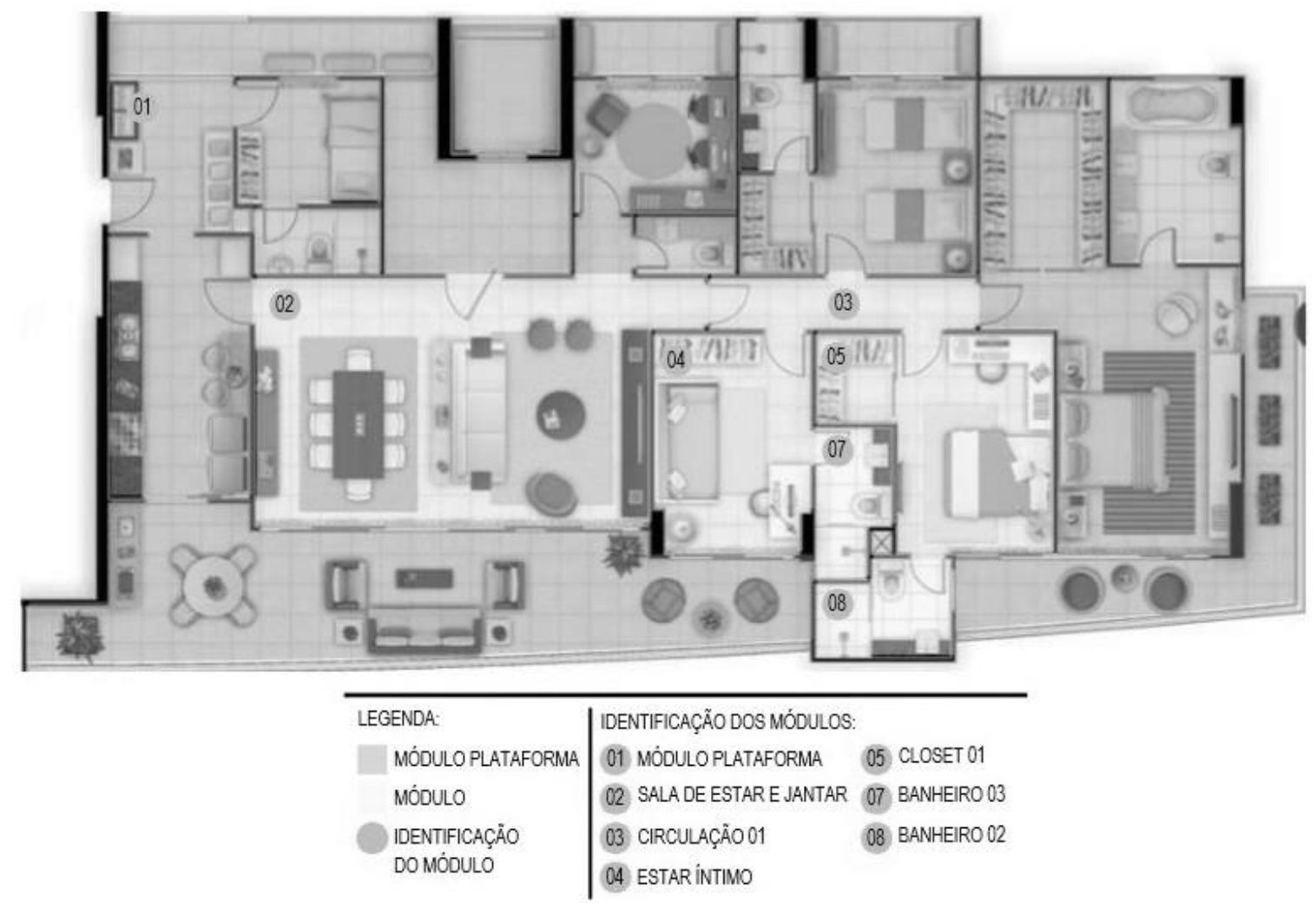

Figura 10 - Identificação dos módulos Opção 2 do empreendimento SBL - estudo de caso 2

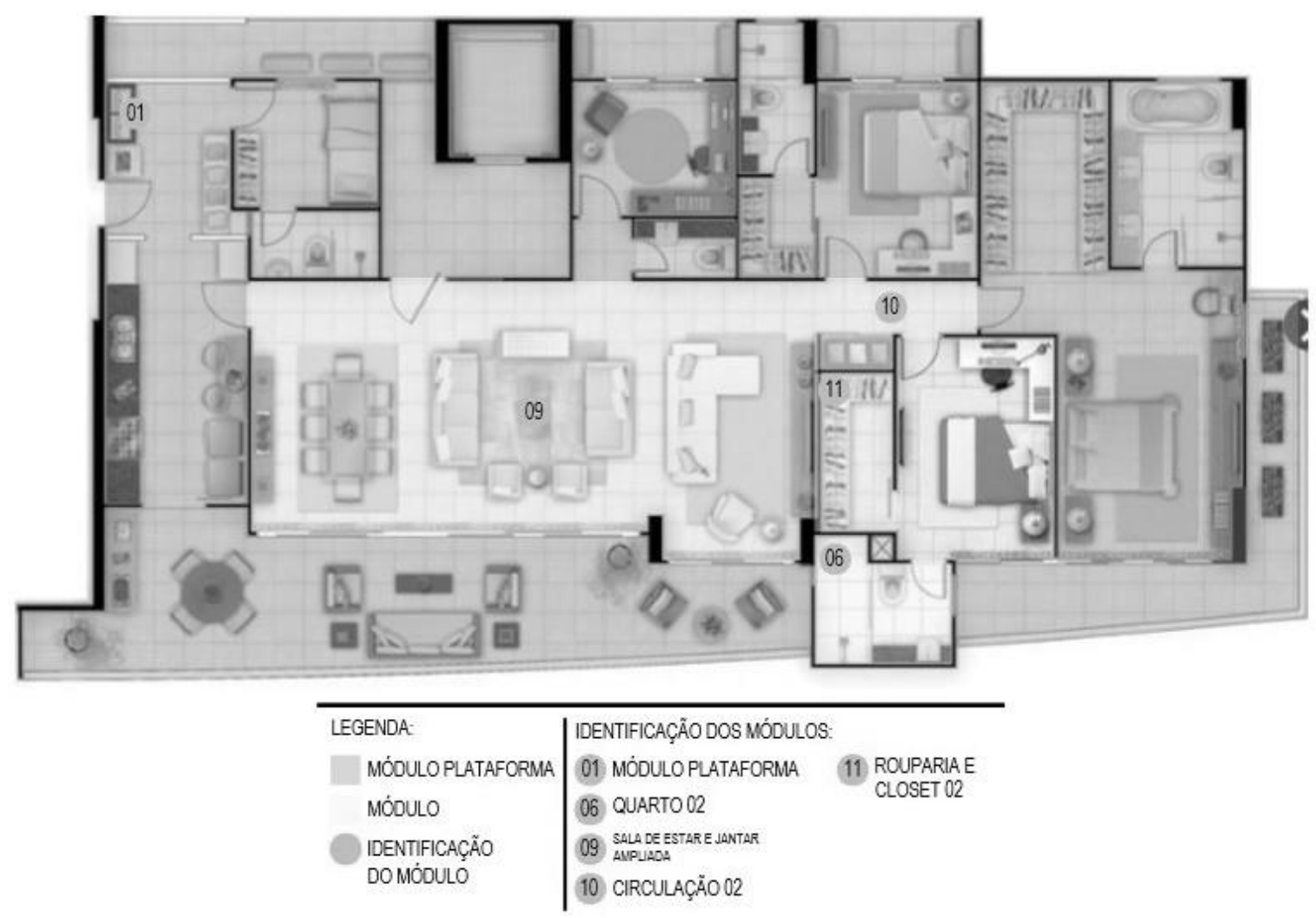

116 Marinho, J. P.; Barros Neto, J. de P. 
Tabela 5 - Módulos do empreendimento SBL - estudo de caso 2

\begin{tabular}{c|l}
\hline MÓDULO & \multicolumn{1}{c}{ AMBIENTE } \\
\hline $\mathbf{0 1}$ & $\begin{array}{l}\text { Plataforma: varandas, sacadas, hall social, cozinha, área de serviço, quarto e banheiro } \\
\text { de serviço, quarto e banheiro de casal, quarto 1, banheiro 1, quarto 2, lavabo e gabinete }\end{array}$ \\
\hline $\mathbf{0 2}$ & Sala de estar e jantar \\
\hline $\mathbf{0 3}$ & Circulação tipo 1 \\
\hline $\mathbf{0 4}$ & Estar íntimo \\
\hline $\mathbf{0 5}$ & Closet 1 \\
\hline $\mathbf{0 6}$ & Quarto 2 \\
\hline $\mathbf{0 7}$ & Banheiro 3 \\
\hline $\mathbf{0 9}$ & Banheiro 2 \\
\hline $\mathbf{1 0}$ & Sala de estar e jantar ampliada \\
\hline $\mathbf{1 1}$ & Circulação tipo 2 \\
\hline
\end{tabular}

Tabela 6 - Famílias de módulos do empreendimento SBL - estudo de caso 2

\begin{tabular}{c|l}
\hline FAMÍLIA & \multicolumn{1}{c}{ MÓDULO } \\
\hline A & 01 (Plataforma) \\
B & 02, 03, 04, 09, 10 \\
C & $05,06,07,08$ e 11 \\
\hline
\end{tabular}

As famílias de módulos estão identificadas na Tabela 6.

Os componentes deverão interagir por meio de suas interfaces. Para Ulrich (1995), podem interagir interfaces geométricas. Porém, no caso do empreendimento SBL, o desenvolvimento das opções de planta apresenta o conceito de arquitetura integral, o que não se adéqua à estratégia de CM, pois a interface entre os módulos exige uma complexidade maior entre o mapeamento, fazendo com que o design do produto seja desenvolvido em uma fase muito inicial do processo de produção, o que compromete os critérios de entrega, de forma semelhante aos produtos produzidos em massa. Salvador (2007) aponta que a modularidade do produto deve proporcionar distintos produtos, porém essas diferenças devem ser minimizadas. No caso do empreendimento SBL, o agrupamento dos componentes não resultou em módulos tão eficazes para a elaboração de diferentes produtos.
A Família $\mathrm{C}$ possui módulos com interações entre as interfaces que exigem modificações de um maior número de elementos, dificultando a mudança entre os módulos. Os módulos 6,7 e 8 (quarto 2, banheiro 3, banheiro 2 respectivamente) exigem que a decisão do cliente seja tomada em uma fase muito inicial do processo de produção, já que há alterações nas instalações hidráulicas. Essa família de módulos não apresentou muitos ganhos no valor agregado, uma vez que na opção 2 houve a supressão de um banheiro e os demais módulos não apresentam muitas diferenças entre as funções. Como podemos observar, a opção 1 é composta de closet e dois banheiros; e a opção 2 é composta de rouparia, closet e um banheiro.

\section{Estudo de caso 2: empreendimento NPC}

O empreendimento NPC é composto de duas torres, T e R. Nas figuras a seguir são identificados os módulos desenvolvidos em cada opção de planta da torre T (Figuras 11 a 14). 
Figura 11 - Identificação dos módulos Opção 1 da torre T do empreendimento NPC - estudo de caso 2

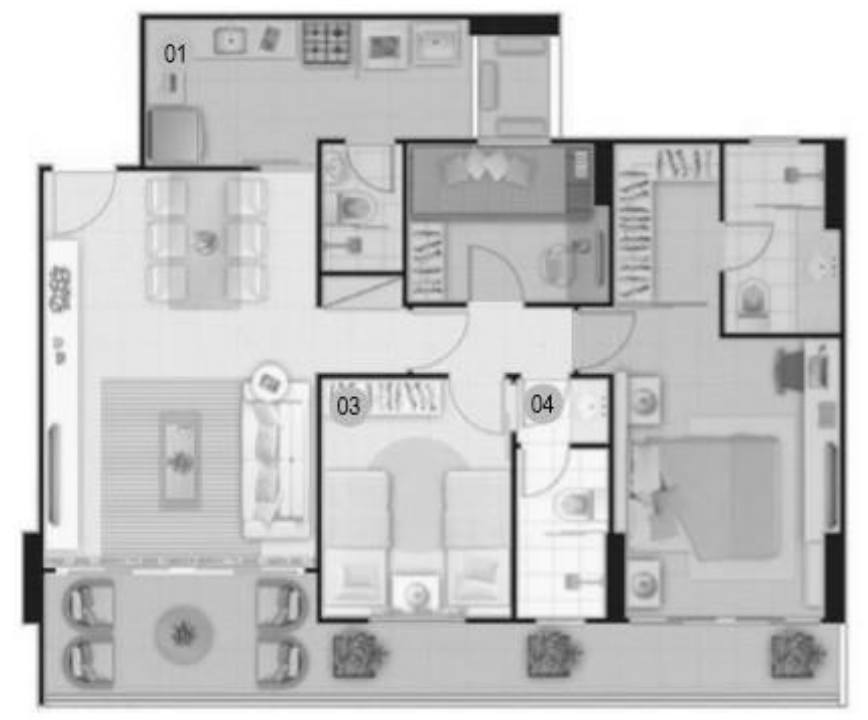

\begin{tabular}{l|l}
\hline LEGENDA: & IDENTIFICAÇÃO DOS MÓDULOS: \\
MÓDULO PLATAFORMA & 01 MÓDULO PLATAFORMA \\
MÓDULO & 02 SALA DE ESTARE JANTAR \\
IDENTIFICACCÃO & 03 QUARTO 02 \\
DO MÓDULO & 04 BANHEIRO REVERSIVEL
\end{tabular}

Figura 12 - Identificação dos módulos Opção 2 da torre T do empreendimento NPC - Estudo de caso 2

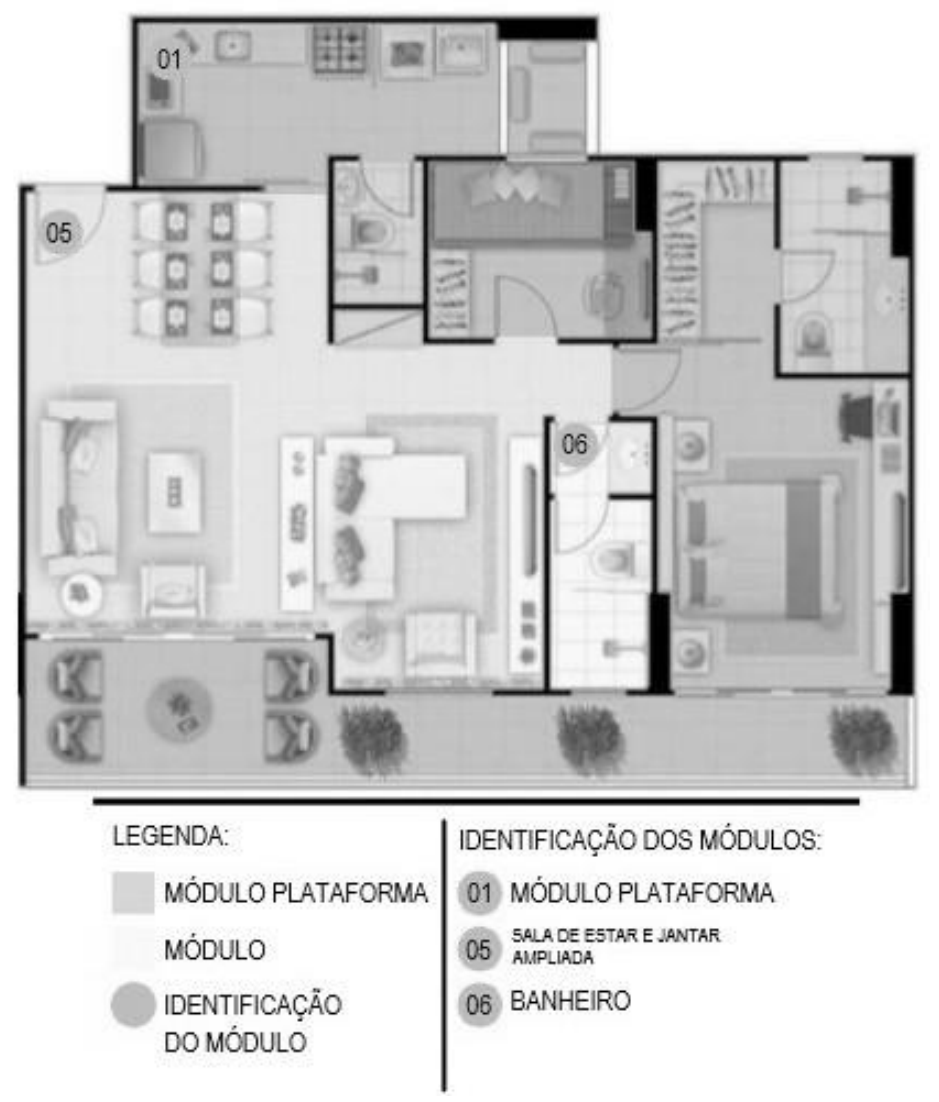

118 Marinho, J. P.; Barros Neto, J. de P. 
Figura 13 - Identificação dos módulos Opção 1 da torre R do empreendimento NPC - estudo de caso 2

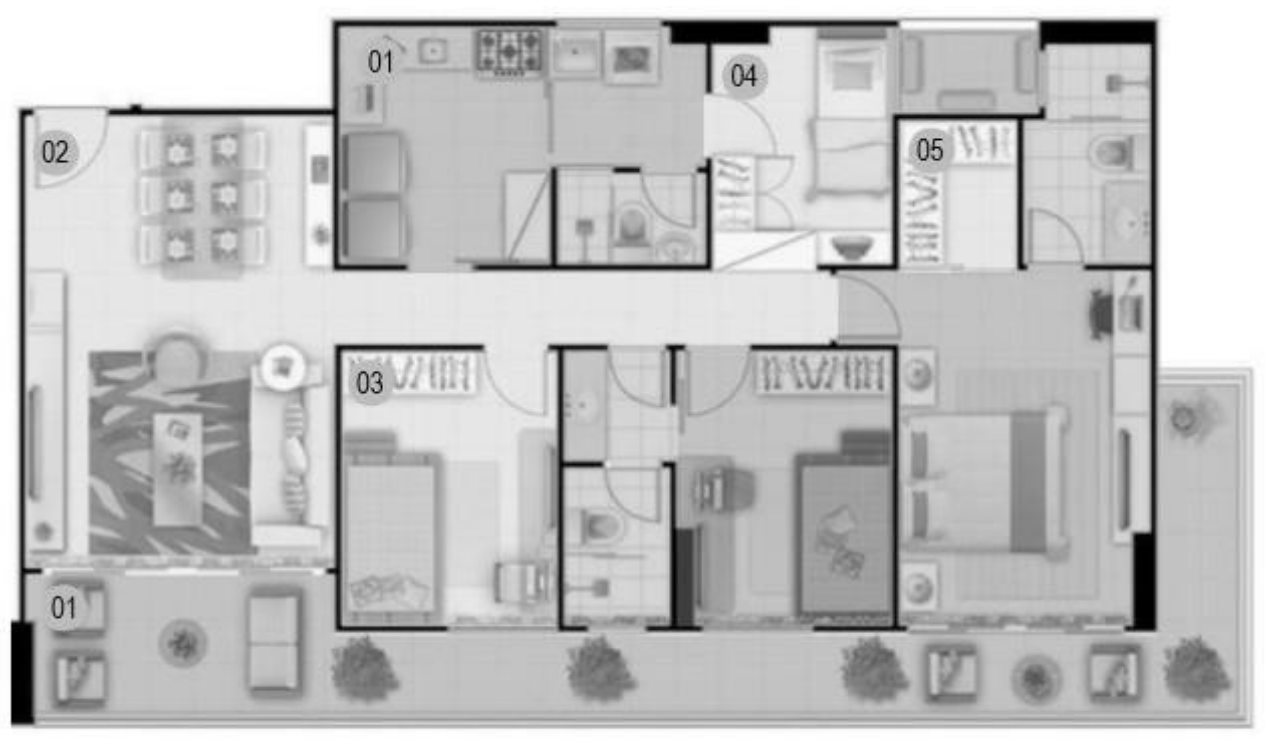

\begin{tabular}{l|l}
\hline LEGENDA: & IDENTIFICAÇÃO DOS MÓDULOS: \\
MÓDULO PLATAFORMA & 01 MÓDULO PLATAFORMA 05 CLOSET 01 \\
MÓDULO & 02 SALA DE ESTARE JANTAR \\
IDENTIFICAÇÃO & 03 QUARTO 02 \\
DO MÓDULO & 04 QUARTO DE SERVIÇO
\end{tabular}

Figura 14 - Identificação dos módulos Opção 2 da torre R do empreendimento NPC - estudo de caso 2

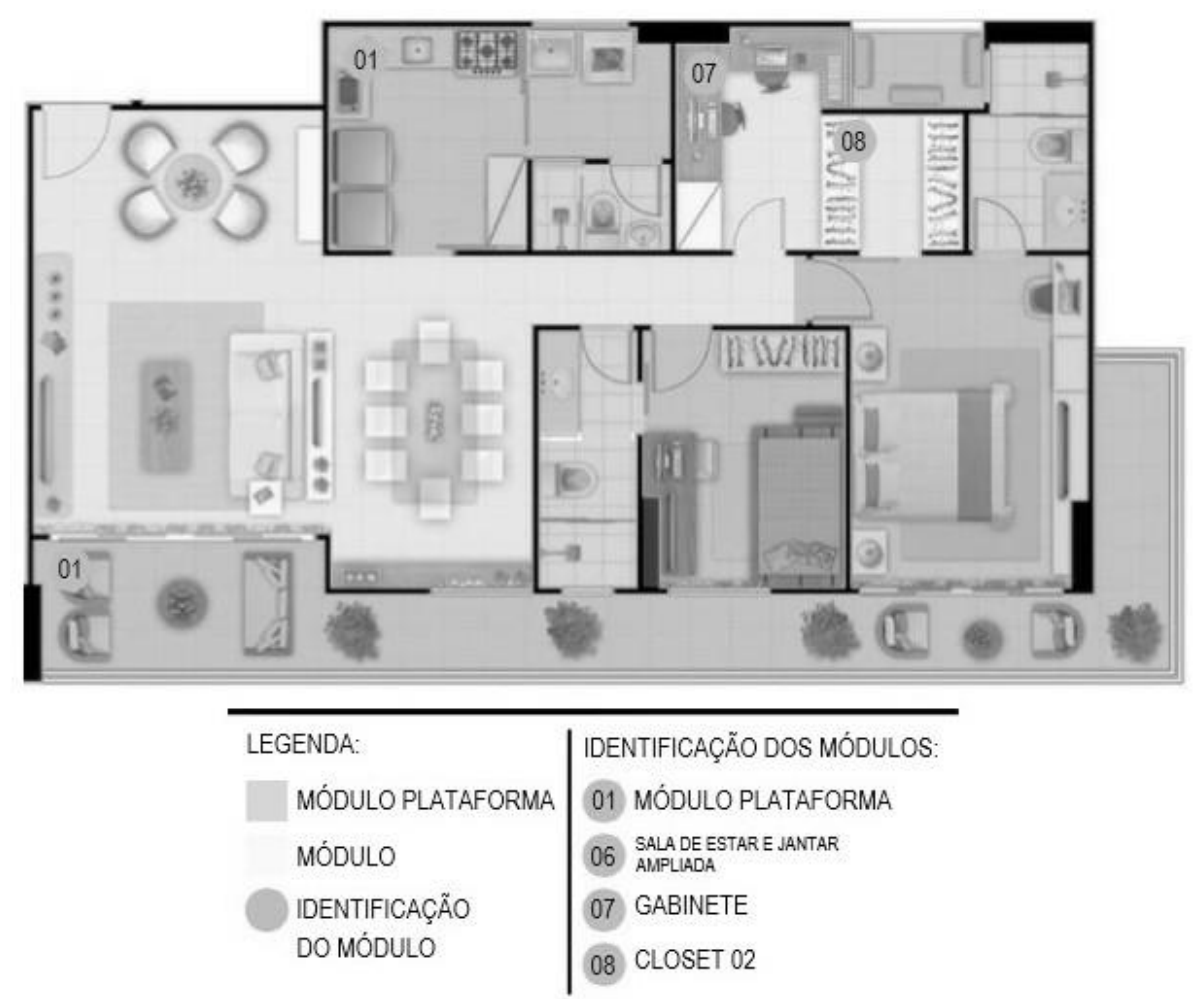


A seguir, na Tabela 7, é apresentada uma lista com todos os módulos identificados nas duas opções.

As famílias de módulos estão identificadas na Tabela 8.

As famílias apresentam interfaces que facilitam a troca de módulos. No entanto, com o desenvolvimento de outros módulos seria possível gerar mais opções de planta ao cliente. Por exemplo, o quarto 2 poderia apresentar outras funções, e o banheiro de serviço poderia servir também ao gabinete.

Em seguida são identificados os módulos desenvolvidos em cada opção de planta da torre R.

Na Tabela 9 é apresentada uma lista com todos os módulos identificados nas duas opções.

As famílias de módulos estão identificadas na Tabela 10.

Tabela 7 - Módulos do empreendimento NPC Torre T - estudo de caso 2

\begin{tabular}{c|l}
\hline MÓDULO & \multicolumn{1}{c}{ AMBIENTE } \\
\hline $\mathbf{0 1}$ & $\begin{array}{l}\text { Plataforma: varandas, sacadas, cozinha, área de serviço, banheiro de } \\
\text { serviço, rouparia, quarto e banheiro de casal e gabinete }\end{array}$ \\
\hline $\mathbf{0 2}$ & Sala de estar e jantar e circulação \\
\hline $\mathbf{0 3}$ & Quarto 2 \\
\hline $\mathbf{0 4}$ & Banheiro reversível \\
\hline $\mathbf{0 5}$ & Sala de estar e jantar ampliada \\
\hline $\mathbf{0 6}$ & Banheiro \\
\hline
\end{tabular}

Tabela 8 - Famílias de módulos do empreendimento NPC Torre T - estudo de caso 2

\begin{tabular}{c|l}
\hline FAMÍLIA & \multicolumn{1}{c}{ MÓDULO } \\
\hline A & 01 (Plataforma) \\
\hline B & 02, 03 e 05 \\
\hline C & 04 e 06 \\
\hline
\end{tabular}

Tabela 9 - Módulos do empreendimento NPC Torre R - estudo de caso 2

\begin{tabular}{c|l}
\hline MÓDULO & \multicolumn{1}{c}{ AMBIENTE } \\
\hline $\mathbf{0 1}$ & $\begin{array}{l}\text { Plataforma: varandas, sacadas, cozinha, área de serviço, banheiro de } \\
\text { serviço, quarto e banheiro de casal, quarto 1 e banheiro reversível }\end{array}$ \\
\hline $\mathbf{0 2}$ & Sala de estar e jantar e circulação \\
\hline $\mathbf{0 3}$ & Quarto 2 \\
\hline $\mathbf{0 4}$ & Quarto de serviço \\
\hline $\mathbf{0 5}$ & Closet casal 1 \\
\hline $\mathbf{0 7}$ & Sala de estar e jantar ampliada \\
\hline $\mathbf{0 8}$ & Gabinete \\
\hline
\end{tabular}

Tabela 10 - Famílias de módulos do empreendimento NPC Torre R - estudo de caso 2

\begin{tabular}{c|l}
\hline FAMÍLIA & \multicolumn{1}{|c}{ MÓDULO } \\
\hline $\mathbf{A}$ & 01 (Plataforma) \\
$\mathbf{B}$ & 02, 03 e 06 \\
$\mathbf{C}$ & 04, 05, 07 e 08 \\
\hline
\end{tabular}

120 Marinho, J. P.; Barros Neto, J. de P. 
Os módulos dessa torre apresentam interfaces que exigem maiores mudanças de elementos para que ocorra a interação entre os módulos. Na Família B a circulação do corredor que se incorpora tanto no módulo 2 (sala de estar e jantar, e circulação) como no módulo 6 (sala de estar e jantar ampliada) apresenta uma mudança de alvenaria do quarto de casal. Nota-se que entre a opção 1 e a opção 2 a alvenaria da porta de entrada do quarto de casal sofre um deslocamento desnecessário, dificultando a mudança de módulos. Na Família $\mathrm{C}$ os módulos 7 e 8 (gabinete e closet casal 2 respectivamente) possuem a mesma função, porém suas interfaces com os módulos 4 e 5 (quarto de serviço e closet casal 1 respectivamente) apresentam grande variedade de componentes, dificultando a criação de mais opções de planta. Seria possível repensar essas interfaces, fazendo com que a Família C fosse composta somente dos módulos 4 e 5 . Já os módulos 7 e 8, como apresentam a mesma função, se tornariam um único módulo, que faria parte da plataforma.

\section{Estudo de caso 3: empreendimento PDV}

A seguir é apresentada a identificação dos módulos em cada opção de planta desenvolvida para o empreendimento PDV da Empresa C (Figuras 15 a 17).

Figura 15 - Identificação dos módulos Opção 1 do empreendimento PVD - estudo de caso 3

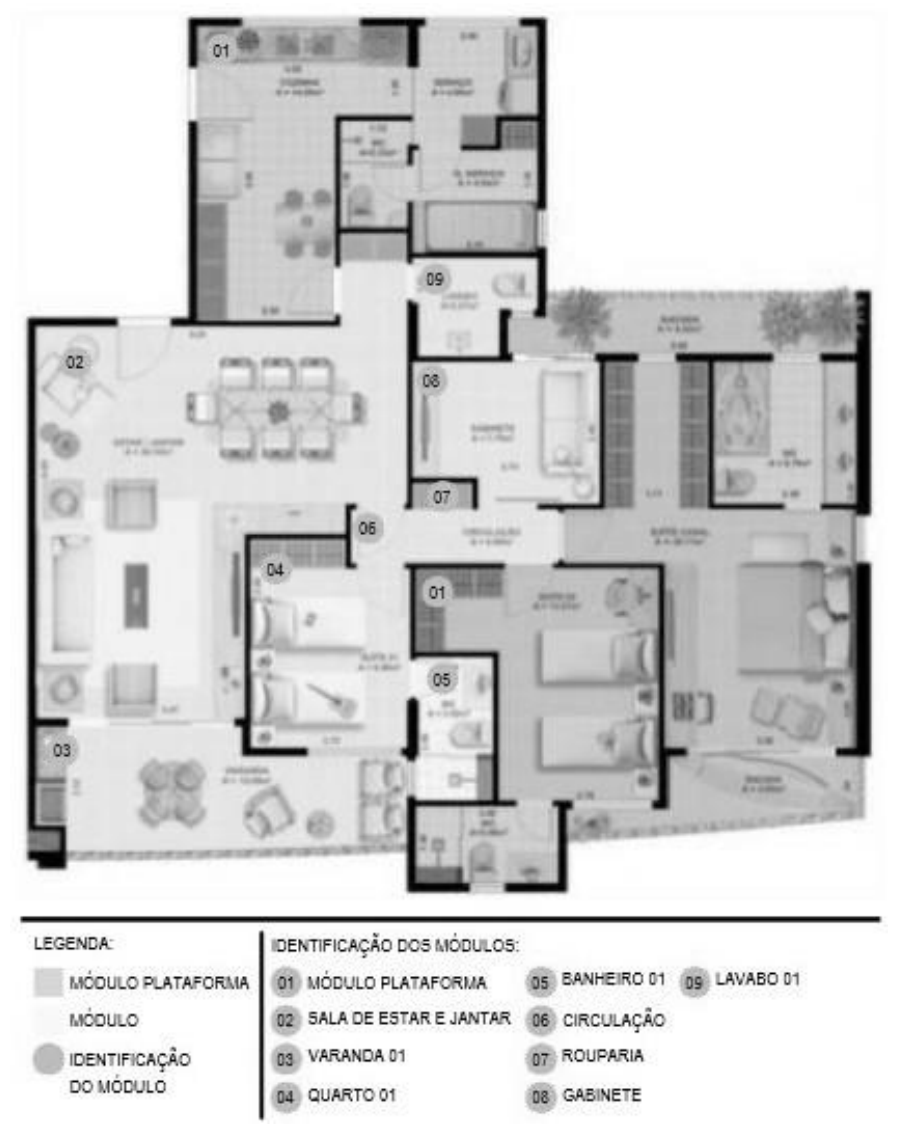


Figura 16 - Identificação dos módulos Opção 2 do empreendimento PVD - estudo de caso 3

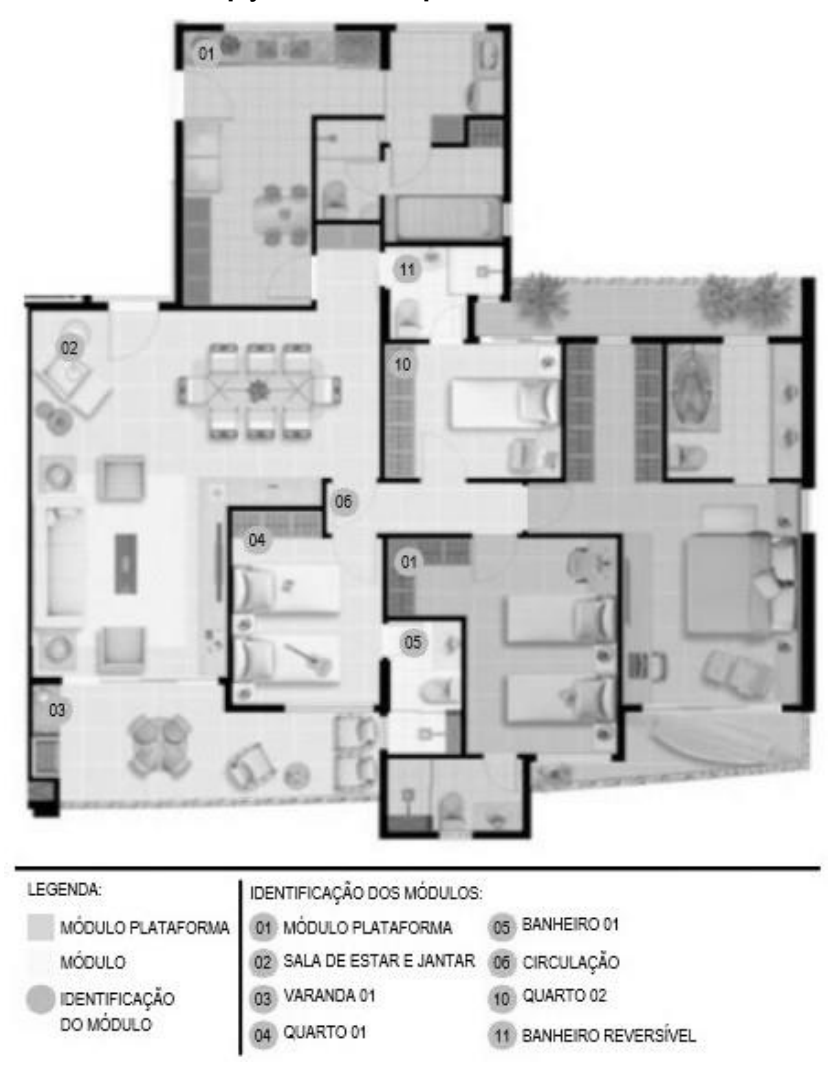

Figura 17 - Identificação dos módulos Opção 3 do empreendimento PVD - estudo de caso 3

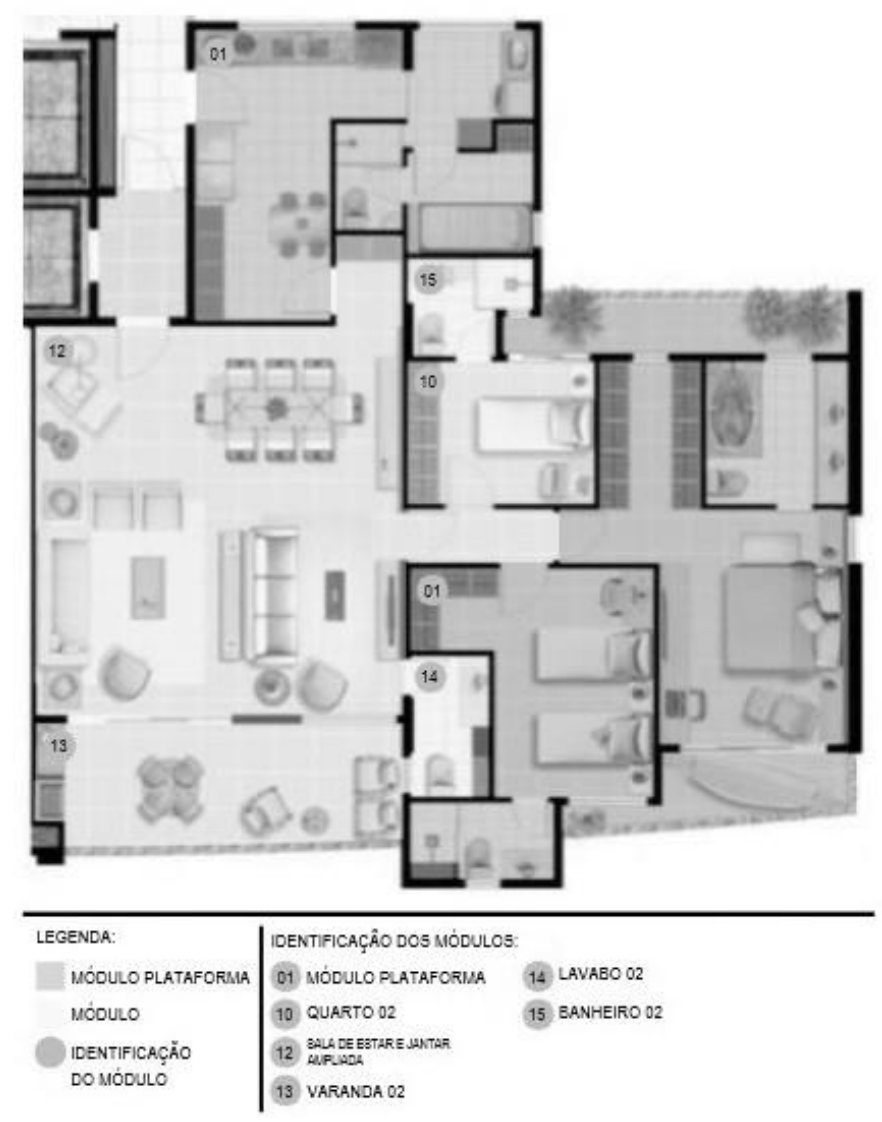

122 Marinho, J. P.; Barros Neto, J. de P. 
Na Tabela 11 é apresentada uma lista com todos os módulos identificados nas três opções.

As famílias de módulos estão identificadas na Tabela 12.

O desenvolvimento dos módulos gerou três opções de planta, e as interfaces entre esses módulos permitem a fácil alteração entre os elementos, possibilitando à Empresa $\mathrm{C}$ a criação de mais opções se assim o desejasse. No entanto, se observarmos os módulos da Família $\mathrm{B}$, não há a possibilidade de intercambialidade entre os módulos 3 e 4, 12 e 13 (varanda 1, quarto 1, sala de estar e jantar ampliada, e varanda 2 respectivamente). Ou seja, o módulo 13 não pode ser utilizado na mesma plataforma que o módulo 4, assim como o módulo 12 não pode ser utilizado na mesma plataforma que o módulo 3. A maior dificuldade enfrentada nesse caso é a definição da estrutura, pois as interfaces desses módulos envolvem a decisão de concretagem das vigas, antecipando ainda mais a decisão do cliente pela opção de planta. Essa situação se torna ainda mais delicada se a unidade ainda não tiver sido comercializada até o momento da execução do serviço. Nesse caso, a construtora executará a opção 1 (definida como padrão), e o cliente que vier a comprar o apartamento após a concretagem somente poderá escolher entre as opções 1 e 2 . É muito importante que durante o desenvolvimento do projeto as interfaces relacionadas às vedações de fachada ou de estrutura possuam uma fácil troca entres os demais módulos, pois isso evitará atrasos ou prejuízos na execução dos serviços. Essa situação poderia ser evitada se houvesse maior interação entre todos os setores envolvidos no desenvolvimento do produto; a análise dos profissionais é fundamental para detectar ou prever interferências no processo.

\section{Estudo de caso 3: empreendimento LMN}

A seguir é apresentada a identificação dos módulos em cada opção de planta desenvolvida para o empreendimento LMN da Empresa C (Figuras 18 a 20).

Tabela 11 - Módulos do empreendimento PDV - estudo de caso 3

\begin{tabular}{c|l}
\hline MÓDULO & \multicolumn{1}{c}{ AMBIENTE } \\
\hline $\mathbf{0 1}$ & $\begin{array}{l}\text { Plataforma: sacadas, cozinha, área de serviço, quarto e banheiro } \\
\text { de serviço, quarto e banheiro de casal, quarto 3 e banheiro 3 }\end{array}$ \\
\hline $\mathbf{0 2}$ & Sala de estar e jantar \\
\hline $\mathbf{0 3}$ & Varanda 1 \\
\hline $\mathbf{0 4}$ & Quarto 1 \\
\hline $\mathbf{0 5}$ & Banheiro 1 \\
\hline $\mathbf{0 7}$ & Circulação \\
\hline $\mathbf{0 8}$ & Rouparia \\
\hline $\mathbf{0 9}$ & Gabinete \\
\hline $\mathbf{1 0}$ & Lavabo 1 \\
\hline $\mathbf{1 1}$ & Quarto 2 \\
\hline $\mathbf{1 3}$ & Banheiro reversível \\
\hline $\mathbf{1 4}$ & Sala de estar e jantar ampliada \\
\hline $\mathbf{1 5}$ & Varanda 2 \\
\hline
\end{tabular}

Tabela 12 - Famílias de módulos do empreendimento PDV - estudo de caso 3

\begin{tabular}{c|l}
\hline FAMÍLIA & \multicolumn{1}{|c}{ MÓDULO } \\
\hline $\mathbf{A}$ & 01 (Plataforma) \\
$\mathbf{B}$ & $02,03,04,06,12$ e 13 \\
$\mathbf{C}$ & 05 e 14 \\
$\mathbf{D}$ & 07,08 e 10 \\
$\mathbf{E}$ & 09,11 e 15 \\
\hline
\end{tabular}


Figura 18 - Identificação dos módulos Opção 1 do empreendimento LMN - estudo de caso 3

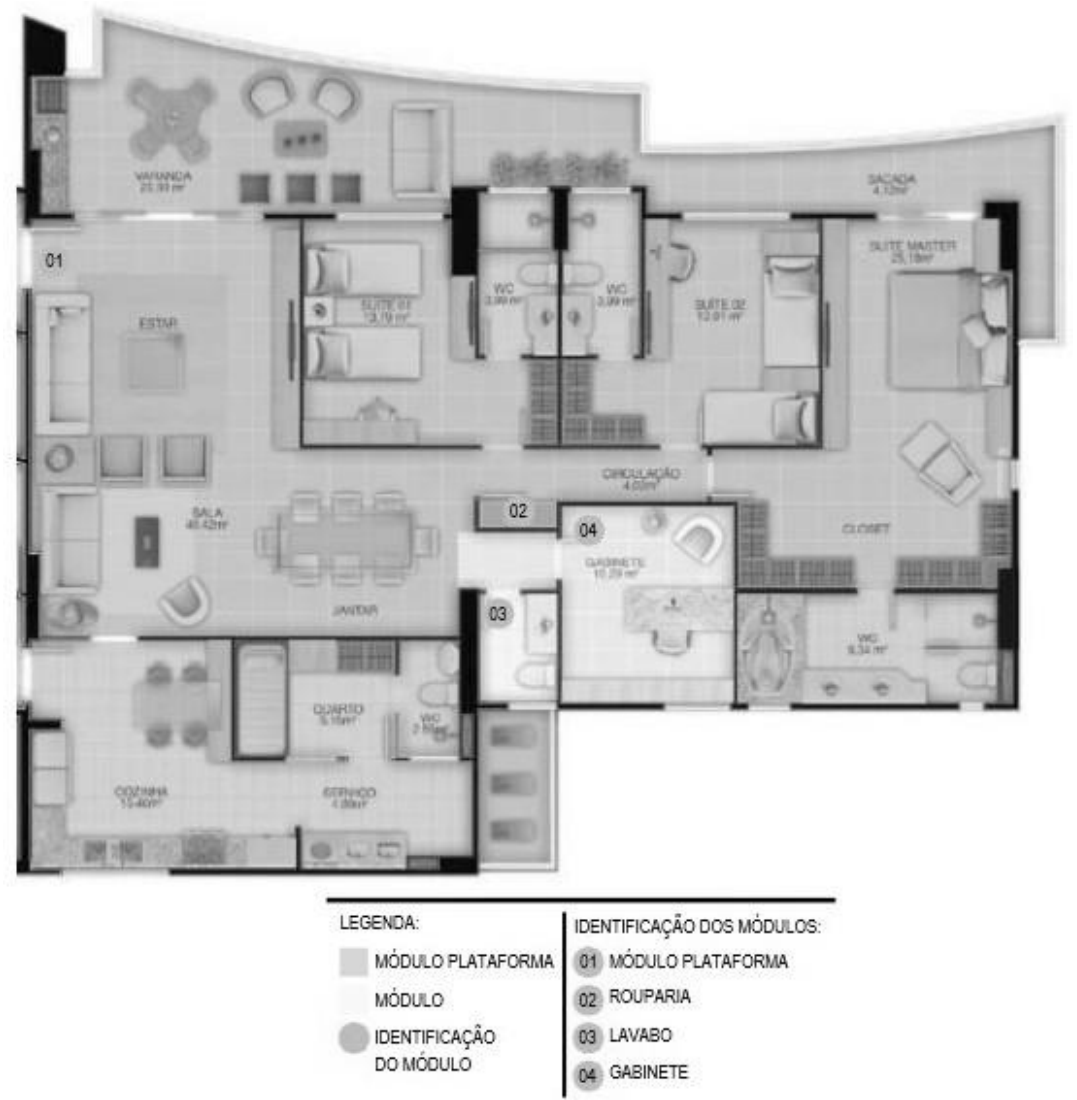

Figura 19 - Identificação dos módulos Opção 2 do empreendimento LMN - estudo de caso 3

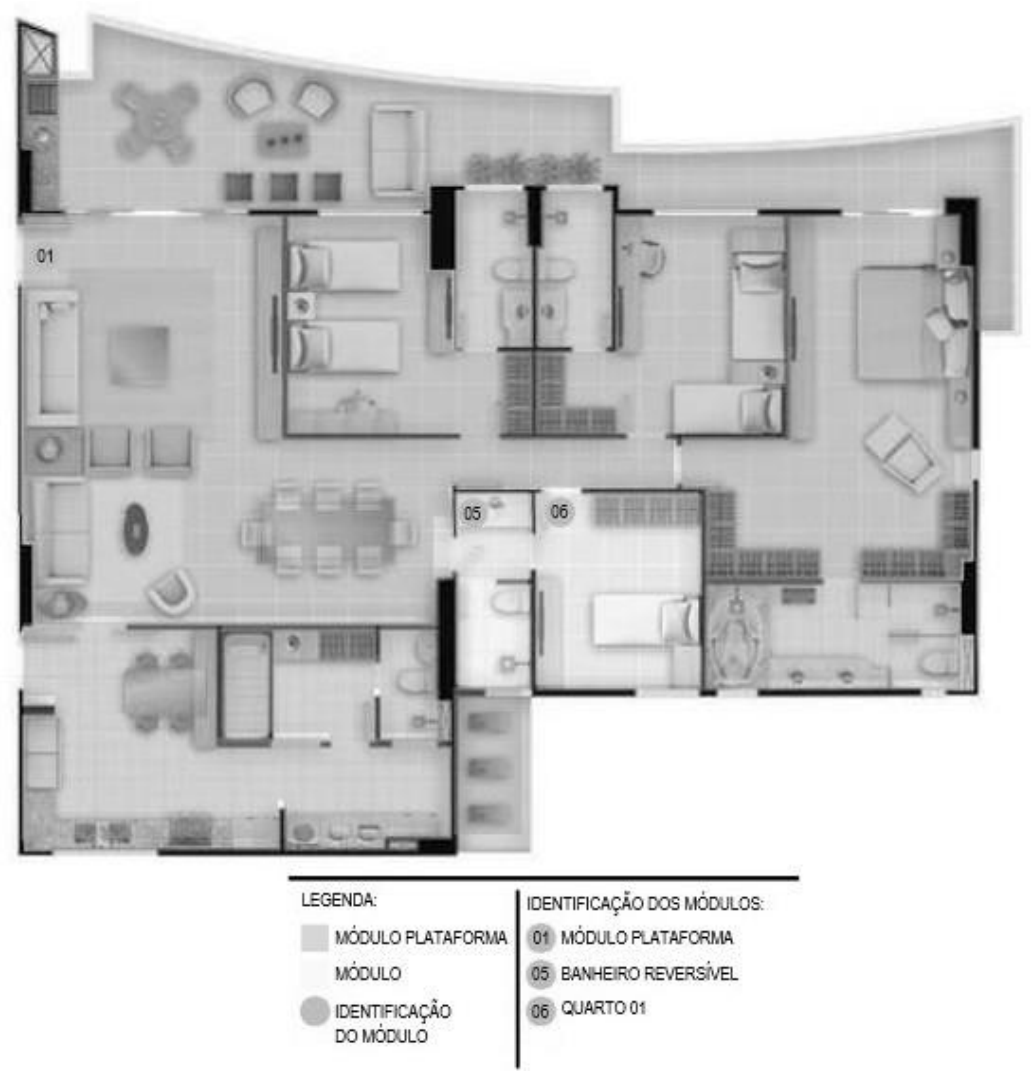


Figura 20 - Identificação dos módulos Opção 3 do empreendimento LMN - estudo de caso 3

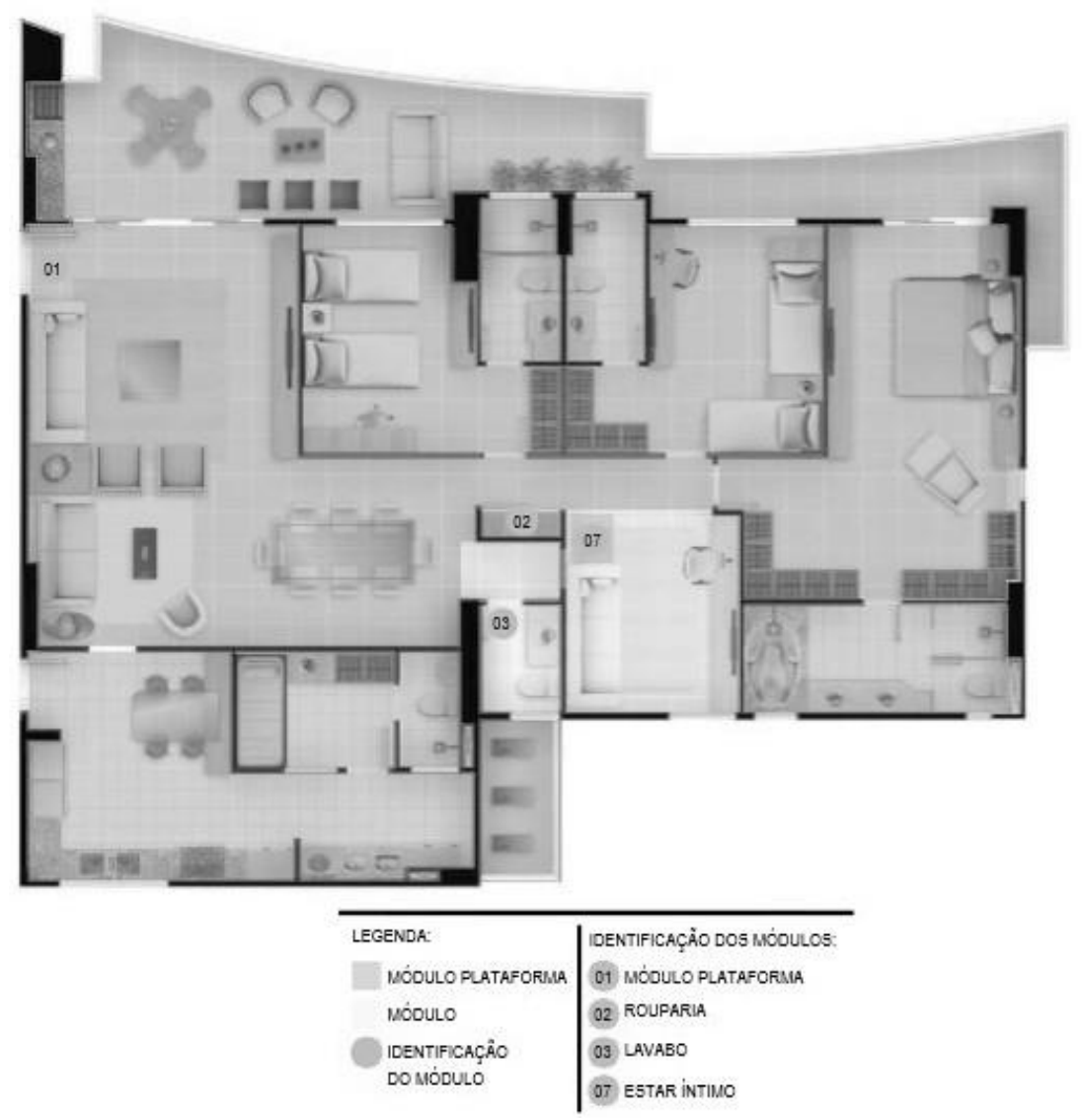

Na Tabela 13 é apresentada uma lista com todos os módulos identificados nas três opções.

As famílias de módulos estão identificadas na Tabela 14.

As opções apresentam boa interação entre os módulos, porém esse conceito foi pouco explorado nesse empreendimento, apresentando apenas um pequeno núcleo de famílias. No entanto, é possível ressaltar que, mesmo com essa pequena quantidade de famílias, é possível elaborar diversas opções de planta.

\section{Análise e proposta de diretrizes para a aplicação de AP no PDP}

Os três estudos apresentam perspectivas similares em relação à aplicação da estratégia de customização nos empreendimentos habitacionais. Os estudos de caso 1 e 2 conseguem atender a diferentes segmentos de mercado utilizando produtos moderadamente diferentes, como sugere Salvador (2007). Nos estudos de caso 2 seria possível criar mais opções de planta se fossem utilizados mais módulos. A seguir, com base na análise dos estudos, são discutidos os principais resultados encontrados e são apresentadas propostas de diretrizes para a aplicação da AP no setor habitacional.

\section{Criação de uma visão integrada}

Durante o desenvolvimento do produto é necessário que todo o processo e seus objetivos finais sejam compreendidos pelos integrantes dessa cadeia. Dessa forma, deve-se evitar a fragmentação de suas operações e adotar a participação de diferentes líderes internos, fornecedores e clientes para criar uma visão integrada das diferentes disciplinas envolvidas. Para que essa integração seja garantida, faz-se necessária a criação de um setor que organize, coordene e articule esses diferentes integrantes, garantindo assim que o objetivo inicial seja atingido.

\section{Focar na geração de valor}

A empresa e seus colaboradores (fornecedores, corretores imobiliários, agências de pesquisa, banco de dados) devem identificar quais são os principais requisitos dos compradores. Isso deve ser traduzido durante o PDP por meio de projetos e ações de relacionamento com o cliente. 
Tabela 13 - Módulos do empreendimento LMN - estudo de caso 3

\begin{tabular}{c|l}
\hline MÓDULO & \multicolumn{1}{c}{ AMBIENTE } \\
\hline $\mathbf{0 1}$ & $\begin{array}{l}\text { Plataforma: varandas, sacadas, cozinha, área de serviço, sala de } \\
\text { estar e jantar, quarto e banheiro de serviço, quarto e banheiro de } \\
\text { casal, quarto 2 e banheiro 2, quarto 3 e banheiro 3 }\end{array}$ \\
\hline $\mathbf{0 2}$ & Rouparia \\
\hline $\mathbf{0 3}$ & Lavabo \\
\hline $\mathbf{0 4}$ & Gabinete \\
\hline $\mathbf{0 5}$ & Banheiro reversível \\
\hline $\mathbf{0 6}$ & Quarto 1 \\
\hline
\end{tabular}

Tabela 14 - Famílias de módulos do empreendimento LMN - estudo de caso 3

\begin{tabular}{c|l}
\hline FAMÍLIA & \multicolumn{1}{|c}{ MÓDULO } \\
\hline $\mathbf{A}$ & 01 (Plataforma) \\
$\mathbf{B}$ & 02, 03 e 05 \\
$\mathbf{C}$ & 04, 06 e 07 \\
\hline
\end{tabular}

\section{Conhecer as possibilidades da estratégia de customização}

É necessário que a empresa conheça a fundo os conceitos e práticas da estratégia de customização, identificando em cada processo como essa estratégia poderá ser aplicada. Dessa forma, deve haver um alinhamento das metas de customização com os processos, pois a aquela norteará as estratégias funcionais da empresa, mediante um trabalho coordenado entre as áreas de marketing, projeto do produto e gerenciamento das operações.

O que se pode constatar através da pesquisa é que nos três estudos de caso as empresas elaboraram, ou estão elaborando, suas estratégias de customização baseando-se principalmente na prática do mercado. Embora as práticas que estejam sendo utilizadas correspondam aos princípios da customização, não há um aprofundamento da teoria na prática e na utilização dessas estratégias, o que cria lacunas que poderão se configurar como entraves em algum momento do processo. Destacamos alguns conceitos de customização que podem ser mais bem explorados pelas empresas estudadas:

(a) planejamento e solução do espaço: as Empresas A e B precisam definir e estabelecer desde os processos iniciais do desenvolvimento do produto quais as estratégias de customização e os atributos do produto que serão customizáveis, propiciando assim um planejamento e uma solução espacial para cada projeto;

(b) coprojeto e requisito dos clientes: a Empresa A define seu público-alvo e desenvolve seu planejamento estratégico baseando-se somente em experiências de empreendimentos anteriores, porém é necessária uma ferramenta de aferição das decisões que são tomadas em relação ao perfil do produto que se deseja desenvolver. A pesquisa de mercado antes e depois do processo é uma importante aliada para determinar quais são esses requisitos e se os objetivos conseguiram ser alcançados ao final do processo. Para isso, cada vez mais é necessário envolver o cliente, de forma a entender melhor suas necessidades, identificando os diferentes segmentos e requisitos;

(c) oferta: as empresas analisadas precisam enfatizar mais as ofertas de customização, principalmente na fase de lançamento do empreendimento, pois essa estratégia é um aliado na comercialização dos produtos e um diferencial no mercado;

(d) menus de escolha: as empresas devem aprimorar e desenvolver interfaces que permitam ao cliente entender e configurar os produtos customizados. Para isso é preciso que as empresas criem mecanismos e canais de comunicação de fácil uso e acesso, para que os clientes visualizem as possibilidades que estão disponíveis; e

(e) retroalimentação: são importantes o acompanhamento e a observação do comportamento do consumidor durante a utilização do produto, pois existem requisitos difíceis de ser expressos verbalmente ou captados por meio de pesquisas. As empresas participantes da pesquisa não deixaram claro em seu PDP a existência de procedimento de retroalimentação dos dados. Porém, ao longo da pesquisa, demonstraram realizar levantamentos a respeito das escolhas dos clientes em relação à customização dos apartamentos. 


\section{Modularização utilizando uma plataforma de produtos}

Rozenfeld et al. (2006) consideram que um aspecto importante é a definição de uma arquitetura aberta ou modular na concepção do produto, o que permite a intercambialidade entre as peças, facilitando a oferta de produtos customizados. A concepção do produto em módulos implica uma mudança na maneira como as empresas concebem o produto e nas técnicas construtivas utilizadas. O ideal na etapa de concepção e projeto seria adotar a estratégia de projeto proposta por Jiao, Ma, Tseng (2001), aumentando a reutilização de projetos e criando uma plataforma de produtos, com base em uma plataforma de componentes ou elementos em comum, compartilhados entre os diferentes produtos. Assim, poderá adiar a decisão do cliente próximo ao fim do processo e gerar menos interferências entre projeto e produção.

\section{Conclusões}

A presente pesquisa propõe melhorias no desenvolvimento de empreendimentos habitacionais a partir da aplicação do conceito de arquitetura do produto. Este estudo foi realizado por meio da aplicação do conceito de customização em massa nesse contexto, destacando mudanças no processo de desenvolvimento do produto. Para tanto foi realizado estudo de caso em três empresas construtoras.

Em cada caso buscou-se identificar as etapas de desenvolvimento dos empreendimentos e a estratégia de customização adotada pela empresa, além de analisar e propor diretrizes para a aplicação do conceito de arquitetura do produto. Nos estudos analisados houve a oportunidade de analisar diferentes estágios de implementação da estratégia de customização e uma reestruturação do PDP.

Por meio dessas constatações atingiram-se três objetivos. O primeiro propõe recomendações para a implementação do conceito de arquitetura do produto no processo de desenvolvimento de empreendimentos habitacionais $\mathrm{O}$ segundo visa elencar os principais entraves e oportunidades para a aplicação desse conceito no processo de desenvolvimento de empreendimentos habitacionais. Por último, o terceiro objetivo identifica melhorias de desenvolvimento do produto através da aplicação do conceito da arquitetura do produto na provisão desses empreendimentos habitacionais.
Durante a pesquisa observaram-se as diferenças e as similaridades do PDP adotado pela empresa. A análise dos processos realizados constatou que são adotadas práticas de customização em massa e como está sendo empregada. Pode-se constatar ainda que essa estratégia é utilizada como forma de oferecer ao cliente uma customização mais planejada, obtendo maior controle sobre as alterações das unidades habitacionais e a produção.

Durante a pesquisa verificou-se que as empresas estavam implantando ou aprimorando a estratégia de customização em massa. Para avaliar a utilização dessa estratégia, na Empresa A foram analisados três empreendimentos, que apresentaram características bem distintas, oferecendo dessa forma uma melhor compreensão dessa mudança de estratégia. Na Empresa B a implantação da estratégia estava na fase inicial, na definição dos parâmetros; já a Empresa C apresentou uma estratégia mais consolidada.

Foi possível notar que as empresas ainda podem utilizar de maneira mais eficiente o conceito de arquitetura do produto na aplicação da estratégia de customização em massa durante o desenvolvimento do empreendimento. Esse conceito pode ser contemplado nas primeiras fases de implantação dessa estratégia. Na etapa final da pesquisa foram propostas diretrizes que as empresas podem adotar para aplicar o conceito de arquitetura do produto para facilitar a utilização da estratégia de customização em massa.

\section{Referências}

\section{AMARAL, D. C. Arquitetura para o gerenciamento de conhecimentos explícitos sobre o processo de desenvolvimento do produto. São Carlos, 2002. Tese (Doutorado em Engenharia Mecânica) - Escola de Engenharia de São Carlos, Universidade de São Paulo, São Carlos, 2002.}

BRANDÃO, D. Q. Flexibilidade, variabilidade e participação do cliente em projetos residenciais multifamiliares: conceitos e formas de aplicação em incorporações. Florianópolis, 1997. 235 f. Dissertação (Mestrado em Engenharia Civil) Escola de Engenharia, Universidade Federal de Santa Catarina, Florianópolis, 1997.

\section{BRANDÃO, D. Q. Diversidade e potencial de flexibilidade de arranjos espaciais de apartamentos: uma análise do produto imobiliário no Brasil. Florianópolis, 2002. 429 f. Tese (Doutorado em Engenharia de Produção) - Escola de Engenharia, Universidade Federal de Santa Catarina, Florianópolis, 2002.}


CAIXA ECONÔMICA FEDERAL. Demanda habitacional no Brasil. Brasília: CAIXA, 2011.

CHAVES, F. J.; LEITE, F. L.; FORMOSO, C. T. Uso de Espaços em Empreendimentos do Programa de Arrendamento Residencial: uma análise de layouts de unidades habitacionais. In: ENCONTRO NACIONAL DE TECNOLOGIA DO AMBIENTE CONSTRUÍDO, 11., Florianopolis, 2006. Anais... Florianópolis: ANTAC, 2006.

DAHMUS, J. B.; GONZALEZ-ZUGASTI, J. P.; OTTO, K. N. Modular product architecture. Center for Innovation in Product Development, Massachusetts Institute of Technology, Cambridge, 2001.

DURAY, R. et al. Approaches to Mass Customization: configurations and empirical validation. International Journal of Operations and Production Management, v. 18, n. 6, p. 605625, nov. 2000.

DU, X.; JIAO, J.; TSENG, M. Architecture of Product Family: fundamentals and methodology. Concurrent Engineering: Research and Application, v. 9, n. 4, p. 309-325, 2001.

FEITZINGER, E.; LEE, H. L. Mass

Customization at Hewlett Packard: the power of postponement. Harvard Business Review, 1997.

HALMAN, J.; VOORDJIK, J.; REYMEN, I. Modular Approaches in Dutch HouseBuilding: an exploratory survey. Housing Studies, v. 23, n. 5, p. 781-799, 2008.

HOFMAN, E.; HALMAN, J.; ION, R. Variation in Housing Design: identifying customer preferences. Housing Studies, v. 21, n. 6, p. 929-943, 2008.

HOFMAN, E.; VOORDIJK, H.; HALMAN, J. Matching Supply Networks to a Modular Product Architecture in the House-Building Industry.

Building Research \& Information, v. 37, n. 1, p. 31-42, 2009.

JIAO, J.; MA, Q.; TSENG, M. M. Towards High Value-Added Products and Services: mass customization and beyond. Technovation, v. 23, n. 10 , p. 809-821, out. 2001.

KOSKELA, L. An exploration towards a production theory and its application to construction. Helsinki, 2000. 296 f. Tese (Doutorado em Tecnologia) - Technical Research Centre of Finland, Helsinki, 2000.
LACERDA, A. E. F.; MARROQUIM, F. M. G.; ANDRADE, S. de S. Avaliação Pós-Ocupação de Unidades Habitacionais do Conjunto Antônio Mariz, João Pessoa-PB. In: SIMPÓSIO BRASILEIRO DE QUALIDADE DO PROJETO NO AMBIENTE CONSTRUÍDO, Rio de Janeiro, 2011. Anais... Rio de Janeiro, 2011.

MACHADO, A. G. C.; MORAES, W. F. A. Estratégias de Customização em Massa Implementadas Por Empresas Brasileiras. In: Produção, v. 18, n. 1, p. 170-183, jan./abr. 2008.

MUFFATTO, M.; ROVEDA, M. Product Architecture and Platforms: a conceptual framework. Department of Industrial Engineering and Management, University of Padua, Padua, 2002.

MUSSI, A. Q. Projeto de HIS Evolutiva: gramática da forma para ampliação da unidade habitacional mínima. In: SIMPÓSIO BRASILEIRO DE QUALIDADE DO PROJETO NO AMBIENTE CONSTRUÍDO, Rio de Janeiro, 2011. Anais... Rio de Janeiro, 2011.

PINE II, B. J. Personalizando produtos e serviços: customização maciça. São Paulo: Makron Books do Brasil, 1994.

ROCHA, C. G. da. A conceptual framework for defining customisation strategies in the house: building sector. Porto Alegre, 2011. 222 f. Tese (Doutorado em Engenharia Civil) - Escola de Engenharia, Universidade Federal do Rio Grande do Sul, Porto Alegre, 2011.

ROCHA, C. G. da. FORMOSO, C. T.; SANTOS, A. do. An Overview of the Customisation Strategies Developed by Four Organisations of the House-Building Sector. In: INTERNATIONAL GROUP LEAN CONSTRUCTION, 20., San Diego, 2012. Proceedings... San Diego, 2012.

ROZENFELD, H. et al. Gestão de desenvolvimento de produtos: uma referência para a melhoria do processo. São Paulo: Saraiva, 2006.

SALVADOR, F.; FORZA, C.;

RUGSTUNSANATHAM, M. Modularity, Product Variety, Production Volume, and Component Sourcing: theorizing beyond generic prescriptions. Journal of Operations Management, v. 20, p. 549-575, 2002.

SALVADOR, F. Toward a Product System Modularity Construct: literature review and reconceptualization. IEEE Transactions on Engineering Management, v. 54, n. 2, p. 219240, 2007. 
SILVEIRA; G. BORENSTEIN, D.; FOGLIATTO, F. S. Mass Customization: literature review and research directions. International Journal of Production Economics, v. 72, n. 1, p. 1-13, jun. 2001.

SILVEIRA, T. C. L.; SANTOS, F. A. N. V., Relações entre a Customização em Massa e o Design de Produtos Industriais. In: Congresso Nacional de Excelência em Gestão, 7., Rio de Janeiro, 2011. Anais... Rio de Janeiro, 2011.

SHIVANAND, H. K.; BENAL, M. M.; KOTI, V. Flexible Manufacturing System. New Age: Nova Delhi, 2006.

TILlMANN, P. A. Diretrizes Para a Adoção da Customização em Massa na Construção Habitacional Para Baixa Renda. Porto Alegre, 2008. Dissertação (Mestrado em Engenharia Civil) - Escola de Engenharia, Universidade Federal do Rio Grande do Sul, Porto Alegre, 2008.

TILlMANN, P. A.; FORMOSO, C. T. Táticas de Customização em Massa Para Produção Habitacional Brasileira: um estudo de caso. In: ENCONTRO NACIONAL DE TECNOLOGIA DO AMBIENTE CONSTRUÍDO, 12., Fortaleza, 2008. Anais... Fortaleza, 2008.

TRAMONTANO, M.; BENEVENTE, V. A. Comportamentos \& Espaços de Morar: leituras preliminares das e-pesquisas Nomads. In: ENCONTRO NACIONAL DE TECNOLOGIA DO AMBIENTE CONSTRUÍDO, São Paulo, 2004. Anais... São Paulo, 2004.
TZORTZOPOULOS, P. The Design and Implementation of Product Development Process Models in Construction Companies. Salford, 2004. 321f. Tese (Doctor of Philosophy) Universidade de Salford, Salford, 2004.

ULRICH, K. The Role of Product Architecture in the Manufacture Firm. Research Police, v. 24, n. 3, p. 419-440, 1995.

ULRICH, K. T.; EPPINGER, S. D. Product Design and Development. 2. ed. Nova York: McGraw Hill, 2000.

VEENSTRA, V. S.; HALMAN, J. I. M.; VOORDIJK, J. T. A Methodology For Developing Product Platforms in the Specific Setting of the Housebuilding Industry. Research in Engineering Design, v. 17, n. 3, p. 157-173, dec. 2006.

XAVIER, R. do N. G.; BARBIRATO, G. M. Análise Quanto à Flexibilidade Espacial de Unidades Residenciais do Conjunto Habitacional em Maceió/AL. In: SIMPÓSIO BRASILEIRO DE QUALIDADE DO PROJETO NO AMBIENTE CONSTRUÍDO, Rio de Janeiro, 2011. Anais... Rio de Janeiro, 2011.

\section{Agradecimentos}

Agardecimentos à Funcap e ao Gercon pelo fomento à pesquisa.

Juliana Pinheiro Marinho

Departamento de Construcão Civil e Engenharia Estrutural | Universidade Federal do Ceará | Campus do Pici, Bloco 710, $2^{\circ}$ andar Fortaleza - CE - Brasil | CEP: 60445-760 | Tel.: (85) 3366-9600 | E-mail: arquitetura.marinho@gmail.com

José de Paula Barros Neto

Departamento de Construção Civil e Engenharia Estrutural | Universidade Federal do Ceará | E-mail: barrosneto@gercon.ufc.br Aranha, 99, Centro | Porto Alegre - RS - Brasil |

CEP 90035-190 | Tel.: (55) 3308-3518 | E-mail: cecilia.rocha@ufrgs.br

Revista Ambiente Construído

Associação Nacional de Tecnologia do Ambiente Construído

Av. Osvaldo Aranha, $99-3^{\circ}$ andar, Centro

Porto Alegre - RS - Brasil

CEP 90035-190

Telefone: +55 (51) 3308-4084

Fax: +55 (51) 3308-4054

www.seer.ufrgs.br/ambienteconstruido

E-mail: ambienteconstruido@ufrgs.br 